\title{
El indiviso del clero. Condiciones de vida del bajo clero secular de Barcelona en 1698
}

\author{
Ignasi Fernández Terricabras ${ }^{1}$
}

Recibido: 2 de agosto de 2021 / Aceptado: 13 de octubre de 2021

Resumen: Análisis estadístico de una relación de 321 eclesiásticos que formaban parte del bajo clero de la ciudad de Barcelona en 1698, distribuidos en once instituciones, de las cuales siete eran parroquias. Se trata de una fuente fiscal que identifica la situación en la que vivía cada eclesiástico y permite realizar comparaciones individuales o entre iglesias que muestran la gran diversidad de situaciones en el bajo clero barcelonés y, a la vez, alguna singularidad en comparación con otras regiones españolas.

Palabras clave: Historia social del clero, Confraternitat de Sant Sever, Barcelona, 1695-1700, indiviso, bajo clero secular, parroquias

\section{[en] The "indiviso" of the clergy. Living conditions of the lower secular clergy of Barcelona in 1698}

\begin{abstract}
The article is a statistical analysis of a list of 321 ecclesiastics who were part of the lower clergy of the city of Barcelona in 1698, distributed in eleven institutions, of which seven were parishes. The document is a fiscal source that identifies the living conditions of each ecclesiastic. Therefore, it allows individual and inter-church comparisons to be made that show the great diversity of situations among the lower clergy of Barcelona and, at the same time, some singularities compared to other Spanish regions.
\end{abstract}

Keywords: Social history of the clergy, St. Sever's confraternity, Barcelona, 1695-1700, indiviso, lower secular clergy, parishes

Sumario: 1. Las sentencias de la Rota romana: el indiviso del clero. 2. La concordia de 1700. 3. El indiviso del trienio 1695-1698. 4. Distribución por comunidades de beneficiados. 5 . El clero parroquial. 6. El bajo clero no parroquial. 7. Los clérigos: doctorado y parentesco. 8. Conclusión.

Cómo citar: Fernández Terricabras, I. (2021). El indiviso del clero. Condiciones de vida del bajo clero secular de Barcelona en 1698, en Cuadernos de Historia Moderna 46.2, 515-542.

Poco se sabe aún de la historia social del bajo clero secular, a diferencia de lo que ocurre con los obispos y los canónigos, cuyos orígenes familiares y hábitos de con-

\footnotetext{
1 Profesor Agregado de Historia Moderna. Universidad Autónoma de Barcelona.

E-mail: Ignasi.Fernandez@uab.es

ORCID: https://orcid.org/0000-0001-5870-2425
} 
ducta ya van saliendo a la luz ${ }^{2}$. La dispersión de los documentos, si existen, el acceso a menudo difícil a los archivos parroquiales y la menor proyección pública de estos clérigos han hecho que los estudios avancen a un ritmo más lento. Apenas se ha progresado en las líneas de investigación sobre el clero secular del siglo XVIII definidas para Cataluña por Roberto Fernández y Pere Fatjó en $1990^{3}$ o, para el conjunto español, por Joan Bada, Arturo Morgado y Antonio Irigoyen ${ }^{4}$.

Un aspecto particularmente poco estudiado es que era común en muchas parroquias, y sobre todo en Cataluña, que el bajo clero se uniera en comunidades de beneficiado ${ }^{5}$, cada uno de los cuales se ocupaba de su beneficio y todos, colegiadamente, del oficio divino en la iglesia ${ }^{6}$. Es aún mucho menos conocido que las comunidades de la catedral y de las parroquias de la ciudad de Barcelona se agruparon en 1548 en una comunidad de comunidades, la Confraternidad de Sant Sever ${ }^{7}$. Ésta, formada por dos representantes de cada parroquia, tenía que defender los intereses del bajo clero secular ante otras instancias, como el cabildo de la catedral o la municipalidad.

\section{Las sentencias de la Rota romana: el indiviso del clero}

En 1603, los procuradores del obispo de Barcelona, de la catedral y del universus clerus dictae Civitatis incoaron una causa contra el Consejo de Ciento (la municipalidad $)^{8}$ ante la Rota romana, alegando que no se respetaba su inmunidad porque se veían obligados a pagar impuestos cuando traían a o compraban en Barcelona productos para ellos o para el culto divino 9 .

2 Bibliografía reciente en Callado, E. (ed.): Gloria, alabanza y poder. Cabildos catedrales hispánicos en la Época Moderna, Madrid, Sílex, 2021.

3 Fernández, R.: "La clerecía catalana en el Setecientos" y Fatjó, P.: "Las haciendas eclesiásticas en la Catalunya del XVIII", en Església i societat a la Catalunya del segle XVIII, Cervera, UNED, 1990, pp. 23-118 y 119-145.

4 Bada, J.: "Iglesia y sociedad en el Antiguo Régimen: el clero secular", en Martínez Ruiz, E. y Suárez Grimón, V. (eds.): Iglesia y sociedad en el Antiguo Régimen, Las Palmas, AEHM - Universidad de Las Palmas de Gran Canaria, 1994, pp. 81-91. Morgado, A.: "El clero en la España de los siglos XVI y XVII. Estado de la cuestión y últimas tendencias", Manuscrits, 25 (2007), pp. 75-100. Irigoyen, A.: "Las aportaciones de la historia de la familia a la renovación de la Historia política y a la Historia de la Iglesia”, en Poblaciones históricas. Fuentes, métodos y líneas de investigación, Río de Janeiro, Asociación Latinoamericana de Población, 2009, pp. 345 362 .

5 Barrio Gozalo, M.: El clero en la España moderna, Córdoba, Cajasur, 2010, pp. 186-191. Para el caso barcelonés, Sacasas, J.: "Origen i consolidació de la comunitat parroquial de Santa Maria del Pi i el seu arxiu", en Splendor Pinensis. Santa Maria del Pi al segle XV, Barcelona, Ateneu Universitari Sant Pacià, 2019, pp. 61-62.

6 Un modelo de estudio en Vilamala, J.: Una Seu, dos col-legis: la comunitat de beneficiats de l'església de la Pietat de Vic (1613-1664), tesis doctoral, Universidad de Barcelona, 2019.

7 Jordi Sacasas ha llamado insistentemente la atención sobre su importancia. Le agradezco enormemente que me informara sobre ella y guiara mis pasos en esta investigación; "La Venerable Confraternitat de Sant Sever de Barcelona, un "sindicat” del segle XVI", Basílica de Santa Maria del Pi. Ahir, avui, demà, no 804, 20/10/2020 (https://basilicadelpi.cat/wp-content/uploads/2020/10/804.pdf).

8 Sobre estas disputas: Dantí, J.: "La hacienda municipal y las exenciones fiscales en Catalunya. El conflicto entre el Consejo de Ciento y los eclesiásticos en Barcelona en los siglos XVI y XVII”, en De Bernardo Ares, J.M. y González Beltrán, J.M. (eds.): La Administración Municipal en la Edad Moderna, Cádiz, AEHM- Universidad de Cádiz, 1999, v. II, pp. 219-228. Sin embargo, la relación del clero con el municipio estaba dominada muy mayoritariamente por la cooperación; Zamora Bretones, Montserrat: La ciudad y el templo: religión cívica en la Barcelona moderna (XVI-XVIII), tesis doctoral, Universidad de Gerona, 2020.

9 Los debates sobre inmunidad del clero en: Fortea, J.I. y Gelabert, J.E.: "Fraude y fisco a comienzos de los tiempos modernos, una historia interminable" y Lavenia, V.: "La Teología y la evasión fiscal (siglos XVI-XVII)", en 
Como suele pasar en Roma, el pleito se eternizó. La Rota se pronunció "in favorem RR.DD. Canonicarum \& Capituli" en 1635. Pero como la sentencia ya nada decía del resto del clero local, la Confraternidad de Sant Sever retomó el litigio hasta que la Rota falló, en 1691, que las franquicias también se les debían aplicar a ellos. Las apelaciones de la ciudad fueron desestimadas con nuevas letras ejecutorias entre 1692 y 1695. Las sentencias precisaban que los munícipes no podían gravar el comercio realizado por los clérigos y sus familiares "bonorum separabilium (...) quam inseparabilium"10.

Sobre los "bienes separables" o "divisibles", hubo rápidamente un acuerdo. Cuando un eclesiástico entrara o saliera en persona de la ciudad con su mercancía, no se le cobraría nada. Cuando lo hiciera uno de sus familiares o alguien en nombre suyo, debería entregar al portalero una póliza impresa y con el sello de la comunidad de beneficiados a la que el clérigo pertenecía en la que constarían las mercancías que introducía o sacaba "per son us y sustent y de las familias". El clérigo que no perteneciera a ninguna comunidad de la ciudad debería aportar una póliza sellada por la Confraternidad de Sant Sever.

El problema estribaba en los "bienes inseparables" o, como dice la documentación en catalán, el "indivís". Cuando un clérigo o sus familiares compraban al por menor dentro de la ciudad una cantidad de un producto que ya había sido gravado con aranceles al ser introducido en ella por el mercader, ¿cómo se les podía devolver la tasa ya pagada por aquella porción de mercancía ${ }^{11}$ ?

Tras largas conversaciones entre los síndicos de la Confraternidad y del Consejo de Ciento, el 2 de enero de 1699 se llegó a un acuerdo para pagar a cada clérigo cierta cantidad según una clasificación que ahora expondremos. Pero el 13 de enero, el vicario general de la diócesis, el canónigo Félix de Taverner y Rubí, nombrado por el cabildo durante la vacante del obispado, exigió al Consejo de Ciento que pagara las cantidades correspondientes a cada beneficiado en diez días ${ }^{12}$. Su monitorio fue percibido como un intento de someter al municipio a la jurisdicción eclesiástica. Hubo más pleitos y, finalmente, la mediación del nuevo obispo de Barcelona, Benet de Sala, que había tomado posesión el 21 de enero de 1699, permitió restablecer la concordia con dos salvedades:

- Se reducirían en una cuarta parte las cantidades previstas, de manera que realmente no se pagó a cada clérigo lo que figura en el documento de Taverner, sino una suma menor ${ }^{13}$.

Fortea Pérez, J.I., Galán Sánchez, Á. y Gelabert, J.E. (eds.): Siete siglos de fraude fiscal en Europa, Santander, Universidad de Cantabria, 2020, pp. 49-80 y 81-116.

10 Las decisiones principales fueron impresas por la Confraternidad: Arxiu Parroquial de la Basílica de Santa Maria del Pi, Barcelona (APSMP), C-745, $\mathrm{n}^{\circ} 34$; C-746, $\mathrm{n}^{\circ} 1$.

11 En Gerona, es al revés: los laicos que alojan a eclesiásticos en sus casas están exentos de tasas municipales cuando compran productos para ellos; Jiménez Sureda, M.: L’Església catalana sota la Monarquia dels Borbons. La catedral de Girona en el segle XVIII, Barcelona, Publicacions de 1'Abadia de Montserrat, 1999, p. 299.

12 Arxiu Històric de la Ciutat de Barcelona (AHCB), 16. 1C.XVIII- 4 / 15, s.f.

13 Un estadillo del Pi que especifica lo que de verdad percibió cada clérigo de la comunidad confirma la rebaja, desde las casi 5 libras del párroco -que solo obtuvo 14 libras 12 sueldos y 6 dineros de las 19 libras 10 sueldos inicialmente asignadas- hasta las 3 libras sobre la tasa del capellán Felip Vert, que "tenía casa parada" y pasó de 12 a 9 libras. APSMP - B 393, s. f.; "Summa del que toca y specta del indivís que la Excma. Ciutat de Barcelona ha pagat y refet als Residents de la Parroquial Iglesia de Sta $\mathrm{M}^{\mathrm{a}}$ del Pi per 3 anys". 
- La Confraternidad renunciaba a reclamar el indiviso anterior a 1695. A cambio, el Consejo de Ciento no exigiría al clero contribuciones por las obras públicas realizadas en ese período.

\section{La concordia de $\mathbf{1 7 0 0}$}

En esos términos, la concordia fue firmada el 5 de abril de 1700 por los representantes de la Ciudad de Barcelona y de la Confraternidad de Sant Sever y confirmada por Clemente XI en 1703. Su particularidad es que el montante que cada clérigo recibe en concepto de recuperación del indiviso varía según su situación, porque se acepta que esta condiciona su nivel de consumo. Así, los contribuyentes son divididos en ocho grupos:

1. 1 libra 10 sueldos al año ${ }^{14}$ : los eclesiásticos que ejercen de maestros "como regularmente solo gastan por su vestir y calzar, a lo que ordinariamente corresponde un derecho muy tenue"15.

2. 2 libras 10 sueldos: los "que paguen la despesa"16, puesto que "además del vestir y el calzar, gastan también por sus alimentos" $" 17$.

3. 3 libras: los que viven en casa de sus padres o de parientes, porque "además de en su manutención y vestir, regularmente gastan y expenden mucho en dichas casas"18.

4. Como quienes mantienen casa propia tienen muchos más gastos, se distingue: 4.1. 4 libras: los que solo tienen una mayordoma.

4.2. 4 libras 10 sueldos: los que viven con "dos personas de familia".

4.3. 5 libras 10 sueldos: los que viven con "tres personas de familia".

4.4. 6 libras 10 sueldos: los que viven con cuatro o más familiares.

En el caso de los clérigos con "casa parada", los aranceles del vino comprado al por menor en las tabernas de la ciudad no estaban incluidos en la tasa y su devolución debía ser reclamada separadamente. Lo mismo sucede con la cera, telas y otros productos comprados "per lo adorno y servey" de su iglesia por cualquier eclesiástico. En cambio, la compra de carne queda excluida del acuerdo, pues existía un pleito pendiente sobre las exenciones por este producto.

La concordia revela el abanico de posiciones del clero urbano, de más a menos humilde. Parece que la situación "natural" a la que debe aspirar el eclesiástico de la ciudad es tener casa propia y, a ser posible, con un pequeño núcleo de "familiares". De hecho, "tenir casa parada" es la expresión que se repite más frecuentemente en

14 Una libra barcelonesa, unidad monetaria catalana, equivalía a 20 sueldos y 1 sueldo a 12 dineros. El sueldo catalán era una moneda de 0’91 gramos de plata.

15 "Com regularment sols gastan per son vestir y calçar, a que ordinàriament correspon un dret molt tenuo".

16 Todavía el Diccionari de la Llengua Catalana (DIEC-2) define dispesa como "casa en la cual se da alojamiento y comida a un grupo reducido de personas por un precio convenido". La expresión estar a dispesa, común en la documentación que manejamos, parece referirse tanto a quien vive en una pensión -con otros huéspedes- como a quien simplemente tiene alquilada una o varias habitaciones de una vivienda. Los eclesiásticos así catalogados reciben la misma cantidad que los que viven "en casa d'altri".

17 "A més del vestir i calçar, gasten també per sos aliments".

18 "A més de son victo y vestir, regularment gasten y expendescan molta cosa en ditas casas". 
estos textos. Según el Diccionario de 1723, fecha próxima a los textos que estudiamos, se entiende por familia "la gente que vive en una casa debaxo del mando del señor de ella", lo cual incluye a parientes y a todo tipo de servidores. El familiar es "el Criado o sirviente de una casa" y, precisa la Academia, su uso "es más común en las casas de los Prelados Eclesiásticos" ${ }^{19}$. En ese sentido, es importante distinguir, tanto en las fuentes primarias como en nuestro texto, cuándo hablamos de la familia consanguínea y cuándo de la "condupticia", es decir, la asalariada ${ }^{20}$.

Es significativ que el acuerdo firmado entre la Confraternidad y la Ciudad no contempla la situación del eclesiástico que vive solo. A tenor de la concordia, el clérigo barcelonés o bien vive en un piso o casa compartida con otros habitantes, o bien, en caso de disponer de una vivienda para uso exclusivo, lo hace como mínimo con una "mayordoma"21. Este rasgo no es exclusivo del clero. Según García Espuche, apenas en el 4’9\% de los fuegos de Barcelona en 1716 habita una persona sola, mayoritariamente viudas, mientras que las familias de dos y tres miembros son el 20 ' $5 \%$ y el $20 \%$ de los hogares, respectivamente. La media es de 4,3 personas por familia $^{22}$. La soledad es rara en la ciudad, tanto entre el clero como entre el laicado ${ }^{23}$.

Cabe notar, sin embargo, que en la documentación del vicario Taverner y en otros documentos posteriores desaparece la mención explícita a las mayordomas ${ }^{24}$. Se habla siempre de clérigos que tienen "casa propia", sin más, dando por descontado que viven solo con un familiar, sin precisar su sexo. Con todo, recordemos que la presencia de servicio doméstico femenino en Barcelona era tan generalizada y transversal que García Espuche ha llegado a llamarla "ciudad de criadas"25.

En la situación opuesta estarían los eclesiásticos que no llegan a mantener una vivienda propia. Deben conformarse con ser preceptores en casa de una familia -a cambio de la manutención, el alojamiento y quizás un pequeño salario- o gozar del uso de una o varias habitaciones en casas de otras personas. Sobre estos últimos, debe tenerse en cuenta la reclamación de un documento municipal anónimo, del que hablaremos en el apartado 7: quien paga "la dispesa", entonces unas 50 o 80 libras al año, no gasta nada más en alimentación, por lo que no merece un retorno del indiviso tan alto como el previsto en la concordia.

19 Diccionario de la Lengua Castellana..., Madrid, Real Academia Española, 1723.

20 Expresión de Jiménez Sureda, op. cit. (nota 11), pp. 283-301. Véase también Gómez Navarro, S.: "La familia religiosa en la España Moderna. Balance y propuesta analítica”, Historia Social, 92 (2018), pp. 119-138.

21 En Cádiz, en 1686, sobre más de 200 clérigos estudiados por Arturo Morgado, solo 6 vivían solos; Morgado, A.: El estamento eclesiástico y la vida espiritual en la diócesis de Cádiz en el siglo XVII, Cádiz, Universidad de Cádiz, 1996, p. 143.

22 García Espuche, A.: Barcelona entre dues guerres. Economia i vida quotidiana (1652-1714), Vic, Eumo, 2004, p. 46.

23 García González, F. (ed.): Vivir en soledad: viudedad, abandono y soltería en el mundo rural (España y América Latina, siglos XVI-XXI), Madrid, Iberoamericana, 2020. En Lucena (Córdoba), en cambio, a mediados del siglo XVIII, un 35\% de los eclesiásticos viven solos; Gómez Navarro, S.: "Familia, estamento e institución: el clero secular en el Reino de Córdoba a mediados del siglo XVIII. El caso de Lucena”, Studia Historica. Historia Moderna, 35 (2013), p. 354. ¿Puede ser indicio de una diferencia entre el medio urbano, donde la vivienda es más cara, y el rural?

24 A pesar de las habladurías populares sobre esta figura, en la archidiócesis de Sevilla el ama de casa del cura solo se ve implicada en el 8\% de los juicios por amancebamiento contra clérigos; Candau, $\mathrm{M}^{\mathrm{a}}$.L.: Los delitos y la penas en el mundo eclesiástico sevillano, Sevilla, Diputación Provincial, 1993, p. 230.

25 Hacia 1700 había unas 2.000 criadas en más de 1.500 casas. Es decir, que un 18\% de los hogares barceloneses, incluidos los de muchos artesanos, tenían servicio doméstico femenino; García Espuche, A.: La ciutat del Born. Economia i vida quotidiana a Barcelona (segles XIV a XVIII), Barcelona, Ajuntament, 2009, p. 58. 


\section{El indiviso del trienio $1695-1698$}

El acuerdo de 1698 entre la Ciudad y la Confraternidad establecía que se pagaría al clero por el gasto del indiviso desde el 17 de diciembre de $1695^{26}$, fecha de la sentencia de la Rota, hasta el 18 de diciembre de 1698. El monitorio del vicario general, firmado el 13 de enero de 1699, conmina a la municipalidad a abonar esas cantidades a 321 eclesiásticos ${ }^{27}$.

Estos aparecen clasificados según la iglesia en la que se encuentra su beneficio. Contamos con las siete parroquias tradicionales de la ciudad, de las cuales solo dos, Santa Maria del Pi y Sants Just i Pastor, conservan actualmente su archivo. La documentación de las otras (Santa Maria del Mar, Sant Pere de les Puel·les, Sant Miquel Arcàngel, Sant Jaume y Sant Cugat del Rec) desapareció durante la Guerra Civil ${ }^{28}$. Pero también se relacionan otros cuatro establecimientos: el colegio de Sant Sever, fundado en 1479 por el clero inferior de la catedral de Barcelona, que no debe ser confundido con la Confraternidad homónima a la que ya nos hemos referido, ni con la Cofradía de Sant Sever que existía en la catedral; la colegiata de Santa Anna, con sus canónigos y "comensales"; el priorato de Sant Joan de Jerusalem y la capilla del Palau de la Comtessa ${ }^{29}$.

La cantidad de clérigos listados es inferior a la que cabría suponer. Según el añorado Joan Bada, la estructura eclesiástica de la ciudad de Barcelona tenía entonces 517 plazas, sin incluir al obispo: 11 dignidades, 36 canónigos ( 24 en la catedral y 12 en Santa Anna), 4 comensales, 1 prior, 8 párrocos o equivalentes, 2 vicarios coadjutores, 375 beneficiados y 80 capellanes $^{30}$. Aunque añadamos a los 321 clérigos de nuestra relación a los 33 canónigos y los 48 oficiales del cabildo que luego mencionaremos, teóricamente nos faltan más de un centenar de clérigos.

Por consiguiente, en 1698 debía haber muchas vacantes y/o beneficiados que no residían en la ciudad, como atestigua la confrontación con documentos de los primeros años del siglo XVIII. Probablemente podemos atribuirlo al cruento sitio de la capital en 1697, durante la Guerra de los Nueve Años ${ }^{31}$ y la ocupación francesa de Barcelona los primeros meses de 1698, así como a la vacante del obispado entre

26 Algunos documentos, sin embargo, hablan del 17 de septiembre de 1695. En la relación de Taverner figuran eclesiásticos incorporados más tarde y que, por lo tanto, cobran menos que los que han servido el trienio entero, pero no se menciona a ninguno en activo en 1695 que ya no lo estuviera en 1698, salvo a Jaume Pons, beneficiado de Santa Maria del Mar, que vivió con dos familiares hasta el 16 de septiembre de 1697.

27 AHCB, 16. 1C.XVIII- 4 / 15, s.f.

28 El sacerdote al frente de cada una de estas iglesias a veces no recibe el título de párroco, sino de "vicario perpetuo" y, en les Puel·les, de "hebdomadario". Un balance de la historiografía sobre las parroquias catalanas: Puigvert, J.M": "Los párrocos y las redes de sociabilidad parroquial en el mundo rural de la Cataluña Moderna: historiografía e historia", Obradoiro de Historia Moderna, 22 (2013), pp. 167-206 y, en el resto de España, Gómez Navarro, S.: "La institución parroquial católica en el Antiguo Régimen. Propuesta de análisis y estado de la cuestión”, Vínculos de Historia, 9 (2020), pp. 246-271.

29 Nombre del antiguo Palacio Real Menor medieval, cedido en el siglo XV a los Requesens, que en el XVII pertenecía a su descendiente, el marqués de los Vélez. En Barcelona no había una corporación de clero secular en la Capilla Real, porque en 1423 el culto en esta había sido confiado a la Orden de la Merced. Fernández Terricabras, I.: "No King for a Palace. Royal Palaces in Barcelona in the Seventeenth Century", en Hortal Muñoz, J.E. (ed.): Politics and Piety at the Royal Sites of the Spanish Monarchy in the Seventeenth Century, Turnhout, Brepols, 2021, pp. 107-108.

30 Bada, J.: "L'origen del clergues barcelonins en el segle XVII (1635-1717). Aproximació estadística", en Homenatge al Doctor Sebastià García Martínez, Valencia, Generalitat Valenciana, 1988, v. II, p. 202.

31 García Espuche, op. cit. (nota 22), pp. 147-199. 
la muerte del obispo Manuel de Alba, el 22 de abril de 1697, y la toma de posesión del obispo Sala, en enero de 1699, que debió interrumpir el ritmo de ordenaciones.

Con todo, casi 400 eclesiásticos seculares, más los regulares destinados en la cincuentena de conventos masculinos y femeninos barceloneses de 1700, son un grupo cuantioso y visible. Según el catastro de 1716, las profesiones más numerosas en Barcelona eran aún las relacionadas con la agricultura: 578 jornaleros y 502 hortelanos. Pero entre los artesanos, los números son menores: 345 zapateros, 338 sastres, 269 tenderos... ${ }^{32}$

A pesar de las ausencias, la fiabilidad del documento que analizamos parece asegurada por algún elemento de comprobación. Por ejemplo, la relación de los miembros de la comunidad de beneficiados del Pi que cobran el indiviso según el documento del archivo de esta iglesia parroquial es la misma que Taverner presenta al Consejo de Ciento $^{33}$. Además, cabe tener en cuenta que esta es la información que se hizo llegar a las autoridades barcelonesas y que, por lo tanto, fue validada por la administración financiera municipal

Cuestión diferente y no aclarada es saber si hay clérigos seculares viviendo en Barcelona que no aparecen en la relación. Podemos hipotetizar la presencia de eclesiásticos de poco rango que, quizás, por no estar insertos en el sistema beneficial de la ciudad, no han dejado rastro en este documento. La única persona mencionada expresamente como foránea es el subdiácono Joan Salvany, beneficiado de la comunidad de Sabadell, "agregada" a la Confraternidad de Sant Sever, que vive de alquiler en Barcelona y cobra su porción del indiviso en Sant Joan de Jerusalem. Puede suponerse la existencia de clérigos residentes con sus familias o ejerciendo otras funciones que no detentasen ningún beneficio en la ciudad, por lo cual no aparecerían en la relación de la Confraternidad, aunque, como miembros del estamento eclesiástico, debieran tener derecho a la exención fiscal

Por ejemplo, dado que la Barcelona del momento es una ciudad con muchos talleres artesanales, doce imprentas y miembros de la oligarquía, parece sospechosamente bajo el número de eclesiásticos que, según la relación, ejercen como maestros en alguna casa: solo 12 de los 321 censados. En la Cataluña moderna, según las últimas investigaciones más alfabetizada de lo que frecuentemente se piensa, era habitual que fueran contratados sacerdotes como maestros particulares o incluso como públicos. También es verdad, no obstante, que en la docencia no participaba solo el clero, sino también estudiantes y maestros laicos ${ }^{34}$.

En torno a 1700, Barcelona cuenta con unos 38.000 habitantes, distinguidos por su heterogénea composición social ${ }^{35}$. Como el resto del Principado, en ese momento está sentando las bases del dinamismo industrial y comercial que la caracterizará en el siglo XVIII ${ }^{36}$. Cierto es que las guerras con Francia, y en especial los recientes bombardeos de la ciudad en 1691 y 1697, han interrumpido coyunturalmente esa

32 García Espuche, op. cit. (nota 22) p. 87. Según sus datos, en 1716 hay 177 clérigos cabezas de casa, lo que se aproxima a los 158 clérigos que, según nuestra relación, tienen familia en 1698, aunque esta última cifra no incluye a canónigos ni oficiales de la catedral

33 APSMP - B 393, s. f.; "Summa...." (nota 13).

34 Ejemplos en García Espuche, A.: La gent del carrer Montcada. Una història de Barcelona (ss. XIII a XVIII), Barcelona, Ajuntament, 2020, v. 1, p. 256, n. 269. Camprubí, X.: Els mestres de minyons i l'ensenyament públic a la Barcelona moderna (ss. XVI-XVIII), en prensa, pp. 24-29 y 151-153.

35 García Espuche, op. cit. (nota 22), p. 56.

36 Simon i Tarrés, A.: Els orígens del miracle econòmic català, Barcelona, Rafael Dalmau, 2021. 
progresión $^{37}$, pero no han alterado las bases estructurales del sistema productivo catalán en general y de Barcelona, en particular, donde se concentra una clase dirigente dinámica que busca a la vez el desarrollo mercantil y el autogobierno político ${ }^{38}$.

Aunque la capitalidad eclesiástica catalana sigue correspondiendo a Tarragona, de cuyo arzobispado la diócesis de Barcelona es sufragánea, la centralidad política y económica de Barcelona en Cataluña no ofrece duda. Y, forzosamente, esa preeminencia convierte a la ciudad en polo de atracción de una parte de la población catalana, también la eclesiástica. Porque, como ha escrito $\mathrm{M}^{\mathrm{a}}$ Luisa Candau, cualquier posibilidad de promoción de un eclesiástico pasa por las ciudades, donde están las curias episcopales, las catedrales, las universidades y las élites ${ }^{39}$. Y eso vale no solo para los clérigos de familias con recursos suficientes, que forzosamente han de aparecer en nuestro documento, sino también para aquellos de orígenes más modestos, mucho más esquivos, que acudían en busca de un modo de ganarse la vida ${ }^{40}$. En definitiva, podemos afirmar que en la relación que estudiamos son todos los que están, pero no están todos los que son, porque, hipotéticamente, pudo existir en las calles barcelonesas cierto proletariado clerical que no sale en la fotografía del vicario Taverner.

\section{Distribución por comunidades de beneficiados}

Según la suma que se deduce del documento estudiado, el desembolso del Consell por este primer pago del indiviso fue importante: 3.448 libras 10 sueldos que se repartieron entre 321 clérigos seculares, de los que contamos con su nombre, apellido y cantidad que les correspondía. Eso quiere decir que, como promedio, a cada uno de ellos se le asignaron más de 10 libras por el trienio $1695-98^{41}$. No es una cantidad despreciable si tenemos en cuenta que en Barcelona el jornal de los maestros artesanos de la construcción era por entonces de 10 sueldos (media libra), aunque el de los oficiales y aprendices era menor, y que una criada mayor de 15 años cobraba entre 7 y 9 libras anuales de salario. Una cuartera de trigo (69'5 litros) costaba casi 3 libras y un pan de 1 libra de peso, 0'41 sueldos ${ }^{42}$.

La mayor parte de esa cantidad, 2.315 libras, se distribuyó entre las siete parroquias de la ciudad, pero de forma muy irregular. Como se puede ver en la Tabla 1, la parroquia más importante y extensa, la de Santa Maria del Mar se lleva ella sola 1.112 libras 8 sueldos, esto es, el $48 \%$ de lo destinado al clero parroquial. No es extraño, pues cuenta a su servicio nada menos que con 105 eclesiásticos. Téngase en cuenta que la siguiente comunidad parroquial en número de beneficiados, la del

37 Espino López, A.: Catalunya durante el reinado de Carlos II, Bellaterra, Universidad Autónoma de Barcelona, 1999.

38 Simon i Tarrés, A.: Del 1640 al 1705. L'autogovern de Catalunya i la classe dirigent catalana en el joc de la politica internacional europea, Valencia, Publicacions de la Universitat, 2011.

39 Candau, M. ${ }^{a}$ L.: La carrera eclesiástica en el siglo XVIII. Modelos, cauces y formas de promoción en la Sevilla rural, Sevilla, Universidad de Sevilla, 1993, p. 361.

40 En las ordenaciones del obispado entre 1635 y 1717 predominan los hijos de artesanos. En un grado menor, los de payeses y miembros de las élites; Bada, op. cit. (nota 30), p. 207.

41 Cálculo teórico exclusivamente con el documento de enero de 1699 . Luego se aplicó una rebaja del $25 \%$ a todos los pagos. En la concordia de 1700 se habla de 328 personas, pero no hemos localizado esta segunda lista.

42 Feliu, G.: Precios y salarios en la Cataluña Moderna, Madrid, Banco de España, 1991. 
$\mathrm{Pi}$, tiene solo 28. Se trata de un dato relevante en una sociedad barroca, en la cual el esplendor del culto estaba relacionado con la fastuosidad y el carácter multitudinario y en la que los clérigos de las distintas iglesias se alineaban por orden a lo largo de las calles principales en las procesiones más vistosas.

A su lado, las dos parroquias más pequeñas quedan bastante deslucidas. Sant Jaume y Sant Cugat apenas reciben 93 libras 10 sueldos (4\% de la parte parroquial) y 52 libras 8 sueldos $(2,2 \%)$, respectivamente. En la primera residen 10 clérigos y en la segunda, solo 6. La situación del rector de Sant Cugat, Josep Sentena, que vive con dos familiares, contrasta con la de los otros cinco eclesiásticos de su parroquia, cuatro de los cuales no tienen casa propia. Aún más la del párroco de Sant Jaume, Joan Comas, que alberga a cuatro familiares, pues solo de uno de los otros nueve servidores de su iglesia nos consta que tenga casa propia, y aun este con un solo familiar.

En una situación intermedia y algo difusa quedan las otras cuatro parroquias urbanas, servidas por entre 20 y 28 clérigos, pero entre ellas se destaca Santa Maria del Pi. Mientras Sant Pere de les Puel·les, que tiene 25 beneficiados, recibe 253 libras 5 sueldos, el Pi, con 28 eclesiásticos, se hace acreedora a 362 libras 12 sueldos. De hecho, a cada clérigo del Pi le correspondía una media de casi 13 libras. Los promedios del priorato de Santa Anna y de la parroquia de Sant Miquel son de 12,3 y 11'3 libras por cabeza, mientras que la media de la ciudad es de 10,7 libras.

Desde luego, queda claro que el párroco del Pi, el Dr. Joan Tolleuda, es sin duda uno de los eclesiásticos más importantes y ricos de la ciudad ${ }^{43}$. En 1698 recibe 19 libras 10 sueldos por haber mantenido durante el trienio a 9 familiares, así como otras 20 libras por los aranceles de la cera y el incienso que él mismo ha comprado para el culto divino. La documentación parroquial posterior muestra que su familiatura oscilará siempre entre 8 y 9 personas, lo mismo que la de su sucesor, el Dr. Jaume Freixa $^{44}$. El nivel de vida de los párrocos de Santa Maria del Pi sobresale en relación incluso con el de los superiores de otras instituciones.

A un nivel de riqueza similar está el prior de la colegiata de Santa Anna, Don Antoni de Bru i Canter, de quien se conserva la petición de 26 libras y 10 sueldos, que justificó de esta manera

por su vestido, calzado y por haber hecho los hábitos de coro o estrado, nieve, pesca, especias, leña, carbón, como por otras cosas necesarias y por haber comprado al por menor dos cargas y media de vino en Barcelona, que son 10 libras. Item lo demás, justa mi conciencia, 16 libras 10 sueldos $^{45}$.

A partir de nuestro documento, no es posible definir una tipología sociológica de las parroquias barcelonesas. Un primer obstáculo es el intrincado mapa parroquial

43 Sobre Tolleuda, Sacasas, J.: "La funció de la parròquia com a centre i nexe social a la ciutat assetjada. L'exemple de Santa Maria del Pi (1705-1730)", en Boada, C. y Brugués, I. (eds.): L’Església a Catalunya durant la Guerra de Successió, Barcelona, Publicacions de l'Abadia de Montserrat, 2015, pp. 111-112.

44 APSMP - B 393.

45 "Per son vestit, calsat y per haver fets los hàbits de cor u estrado, neu, pesca, especies, llenya, carbó, com per altres coses necessarias y per haver comprat a la menuda dos carregas y mitja de vi dins Barcelona, que són 10 11. Item lo demes justa ma conciencia 1611 10"; AHCB, 16. 1C.XVIII- 4 / 15, s. f. Una carga de vino equivale a 121,4 litros. En la relación de Taverner, el prior es el primer nombre mencionado, separado de los canónigos de Santa Anna. 
de Barcelona, cuya delimitación exacta es aún mal conocida ${ }^{46}$, pero que en ningún caso es homogénea ni geográfica ni socialmente. El segundo, la particular distribución económica de una ciudad en la que, a diferencia de otras urbes, los diversos grupos sociales comparten vecindad $y$, aunque hay diferencias territoriales de renta, no existen calles exclusivamente para ricos y los niveles de ostentación social son comedidos $^{47}$.

Muchos estudios de Albert García Espuche y Manuel Guàrdia Bassols han mostrado que, hasta la urbanización de la Rambla a finales del siglo XVIII, en la ciudad de Barcelona el peso del sector oriental es muy superior al occidental. Al este, con una estructura viaria densa y calles cerradas por casas estrechas y altas, se concentran la población y las principales actividades económicas: el mercado (el Born), la principal canalización de agua (el Rec Comtal), a cuya vera se agrupan las manufacturas textiles, y las profesiones relacionadas con el mar (estibadores o pescadores, pero también mercaderes o cambistas). Resulta así que, en el entorno de Santa Maria del Mar, en apenas el 14\% de la superficie de la ciudad vive el $41 \%$ de la población, porcentaje que guarda una reveladora proximidad con el que hemos señalado sobre la cuota del indiviso que le corresponde a la parroquia.

Colindante con ese centro económico, hay otro político, de hecho más céntrico sobre el plano, que mantiene la continuidad con la vieja ciudad romana, donde se hallan las sedes del poder civil (Plaza de San Jaime) y eclesiástico (la catedral). En esa zona con menos densidad de población, que se proyecta hacia el puerto y las distinguidas casas de la calle Montcada, viven muchos notables de la ciudad (nobles, ciutadans honrats, juristas... $)^{48}$. Pero en la misma calle Montcada, por poner un ejemplo bien conocido, también tiene su domicilio un grupo importante de artesanos (sombrereros, drogueros, etc. $)^{49}$.

Es lógico, pues, que las parroquias de Santa Maria del Mar y del Pi, que atienden a la población de esos dos centros, el comercial y el político, sean las más ricas. Pero aun así, son circunscripciones en las que hay diferencias sociales importantes entre los feligreses y, por lo tanto, es lógico que también las haya entre los beneficiados parroquiales.

\section{El clero parroquial}

Para nuestro análisis no importa tanto el importe asignado a cada eclesiástico como su situación personal y su valor como indicador del nivel de vida. Ya hemos señalado que la clasificación acordada marca una nítida delimitación entre los clérigos que "tienen casa propia", ya sea formada por una persona o por más familiares, y aquellos que no disponen de ella. Las tablas 3 y 4 muestran cómo se divide el clero parroquial barcelonés: mientras 89 eclesiásticos no disponen de casa, otros 110 sí

46 Aproximaciones: Guàrdia Bassols, M. y García Espuche, A.: "Estructura urbana", en Sobrequés, J. (dir.): Història de Barcelona, Barcelona, Ajuntament, 1992, v. 4, p. 69, plano 17 y, para la parroquia del Pi, Sacasas, op. cit. (nota 43), p. 104. La localización de las principales iglesias en García Espuche, op. cit. (nota 25), p. 63.

47 García Espuche, op. cit. (nota 34), pp. 43-51.

48 Sobre esas categorías sociales y su movilidad en Cataluña: Amelang, J.: La formación de una clase dirigente. Barcelona, 1490-1714, Barcelona, Ariel, 1986 y Molas, P.: La burguesía mercantil en la España del Antiguo Régimen, Madrid, Cátedra, 1985, pp. 150-161

49 García Espuche, op. cit. (nota 34), pp. 43 y ss. 
la poseen, a los que habría que añadir 7 más que, en el transcurso del trienio, han logrado montar su casa, por lo cual cobran dos tasas diferentes proporcionalmente al tiempo que corresponde a cada situación ${ }^{50}$.

De los 110 clérigos con casa, solo 2 tienen una familia de más de cinco personas, ambos en la parroquia del Pi (el rector Tolleuda y el Dr. Jacinto Solanellas, con seis familiares). En cambio, son ya 8 los clérigos que mantienen a cinco familiares, de los cuales 5 en Santa Maria del Mar. Esta parroquia se destaca en el grupo de eclesiásticos con tres familiares ( 8 de un total de 15$)$, pero en cambio no presenta a ninguno con cuatro familiares. Estos, otros 12 clérigos, se distribuyen por el resto de la ciudad. En total, pues, 37 beneficiados parroquiales viven con tres familiares o más.

El grupo mayoritario de los clérigos con casa propia lo forman los que moran con dos (34) o con un solo familiar (36). Estos 70 clérigos constituyen pues el 63'6\% del clero parroquial con vivienda propia, aunque la media (atención: solo de los clérigos que tienen familia) es de 2,3 personas ${ }^{51}$. De nuevo, merece especial atención Santa Maria del Mar, no solo por las 36 personas en esta situación, sino porque habría que sumarles los 4 eclesiásticos de esa parroquia que entre 1695 y 1698 consiguieron montar una casa y los dos que disminuyeron la familia en algún miembro, pero sin dejar de tenerla.

Como hemos visto, participan en el culto de las parroquias 89 clérigos que no disponen de familiares condupticios. De estos, la categoría más modesta es la de los 8 maestros particulares, 7 de los cuales en Santa Maria del Mar, aunque, como ya hemos dicho, es posible que esta categoría se vea subestimada en nuestra relación. Los que viven "a despesa" (36) o en "casa d'altri" (4) constituyen casi la mitad de nuestro grupo, de los que 18 viven también en esa iglesia. De la otra mitad, los 41 clérigos ( 21 de ellos en Santa Maria del Mar) que viven en casa de sus parientes, trataremos en el apartado 7.

A escala parroquial está claro que el Pi cuenta con el porcentaje de clérigos más pudientes. El 67'8\% de sus eclesiásticos (19) tienen familia propia, 7 de los cuales compuesta por tres o más personas. También la parroquia de Sant Miquel se encuentra en una posición similar: de los 12 eclesiásticos con familia, 7 superan los dos convivientes. En este caso, sin embargo, el porcentaje de los clérigos con familia se sitúa ligeramente por encima de la mitad de los beneficia os $(57 \%)$, como también sucede en Sants Just i Pastor (55\%) y Sant Pere de les Puel-les (52\%). En fin, solo en las parroquias de Sant Jaume y Sant Cugat el porcentaje de beneficiados sin familia supera de mucho al de los pocos eclesiásticos (4 sumando ambas parroquias) que alcanzan a mantener una familia.

\section{El bajo clero no parroquial}

En la relación aparecen cuatro establecimientos sin jurisdicción parroquial. Tres tienen un carácter minoritario y sus miembros parecen llevar un tren de vida más holgado que la mayoría del clero parroquial. En la colegiata de Santa Anna no parece haber gran diferencia entre los canónigos y los comensales, cuya situación familiar es parecida. Sus 17 miembros (excluyendo al prior) cobran cada uno un promedio de 12,3 libras (ver Tabla1). Los 10 eclesiásticos del priorato de Sant Joan de Jerusalem

50 De 5 clérigos, agrupados como "desconocido" en la Tabla 3, no ha sido posible precisar la situación.

51 Igual que la que se da en Santiago de Compostela, pero más baja que en Murcia (ver apartado 8). 
y los 16 del Palau de la Comtessa se mueven también en promedios de 11 y de 12,6 libras por persona respectivamente.

En estas tres corporaciones, los clérigos que tienen casa propia superan a los que no la poseen: 24 por 17. Es en el Palau de la Comtessa donde hay familias más numerosas. El maestro de capilla vive con diez personas, pero señalemos que, como en todas las capillas de música, las ordenanzas le obligan a mantener en su casa a los escolanos. Además, el capellán mayor tiene cinco familiares y 3 beneficiados, otros tres. A falta de estudios particulares, no se puede deducir si ello se debe a un supuesto carácter más aristocrático de la institución, a pesar de que ningún beneficiado vive en casa de parientes, o a la presencia en ella de una importante capilla de música en la que convivían músicos laicos y clérigos, ya fuesen estos beneficiados de la iglesia o contratados. De hecho, la Comtessa es la única comunidad en la que el número de personas que deben cobrar el indiviso (16) supera su plantilla teórica de benefici dos, que oscila entre 13 y 14 según las fechas ${ }^{52}$.

Tampoco parece tan aristocrático como se podría pensar el priorato de Sant Joan de Jerusalem, cuyos clérigos tienen familias relativamente reducidas. En la colegiata de Santa Anna, en cambio, las familias de los 10 clérigos que la tienen son de entre 2 y 4 personas, lo cual contrasta decididamente con la situación que hemos descrito en las parroquias. Otro rasgo que la diferencia es que 5 de los 17 beneficiados viven en casa de sus parientes ( 4 en casa de uno o ambos progenitores y 1 en casa de su hermano).

Caso completamente diferente es el colegio de Sant Sever. Junto con las dos parroquias más pequeñas de la ciudad, es el único establecimiento en el que los clérigos que no tienen familia superan a los que sí viven con ella. De aquellos 39, solo uno consigue cambiar de posición durante el trienio y 15 de ellos viven en pensión o como maestros. De los otros 24,9 viven solo con una persona de familia y 5 con 2 , aunque también sorprende que 8 dispongan de tres familiares y 2 incluso de cuatro. Nuevamente, dentro de unas tendencias generales, hay que admitir una gran amplitud de casos.

Estos resultados responden a la función del colegio como agrupación del estrato clerical más bajo de la catedral, donde las diferencias de jerarquía y renta eran manifiesta ${ }^{53}$. En ese sentido, hay que tener en cuenta que mientras que en las otras comunidades de la lista están incluidos todos los beneficiados al servicio de la iglesia, desde su superior hasta el último llegado, en la catedral el Colegio de Sant Sever tiene otras corporaciones por encima.

No hemos encontrado de momento los datos del indiviso pagado al resto de clero catedralicio en $1695-98^{54}$, pero sí pueden servirnos como elemento de comparación los de $1702-1704^{55}$, cuando cobran 1.498 libras 3 sueldos de la ciudad 33 dignidades

52 Rifé, J.: "La música al Palau de la Comtessa de Barcelona durant el govern de l'Arxiduc Carles d'Àustria a Catalunya (1705-1714)", Revista Catalana de Musicologia, 2 (2004), pp. 131-143. Bien es verdad que 4 de los clérigos aparecen como "músicos asalariados" y que, como veremos luego, según el Consejo de Ciento, en realidad dos de ellos, Joan Baptista Clavell y Esteve Frau Vell, eran laicos.

53 Fatjó Gómez, P.: La catedral de Barcelona en el siglo XVII: las estructuras y los hombres, tesis doctoral, Universidad de Barcelona, 2000.

54 Salvo algunos memoriales en AHCB 16/1C.XVIII-1.2/1.

55 AHCB, 16/1B.XII-35, f. 323-502. Estos no cobran según las tasas del bajo clero, sino en base a una declaración personal en conciencia de cada clérigo sobre lo que debe recibir, lo que impide conocer el tamaño de sus familias. 
y canónigos, así como 48 oficiales, es decir, 81 personas. Si les unimos, a efectos contables, los 63 colegiales de Sant Sever mencionados, podemos fijar el total del clero catedralicio en el no despreciable número de 144 personas. Su organización piramidal se traslada al cobro del indiviso. Cada canónigo recibe, como promedio, 25 libras y cada oficial, 13,9, aunque hay grandes diferencias entre ellos. En cambio, los 63 colegiales de Sant Sever cobran de media 9,7 libras, 1 libra por debajo del promedio del clero secular barcelonés. Como se ve en la Tabla 1, lo que paga la ciudad al alto clero capitular en 1705 se acerca a la mitad de lo que debería haber pagado a todo el bajo clero secular en 1699, cuando en realidad aquellos constituyen solo una cuarta parte de los efectivos. Estas diferencias parecen equiparables a las del resto de España. En Sevilla, por ejemplo, se ha estimado que la diferencia media de riqueza entre un canónigo y un cura era de 2 a $1^{56}$.

Es útil comparar las dos corporaciones más numerosas de la ciudad. En el Colegio de Sant Sever y en la parroquia de Santa Maria del Mar encontramos las ratios más altas de clérigos que ejercen como maestros, viven en pensión o con parientes, es decir, aquellos a quienes, salvando todas las excepciones, se puede considerar en condiciones más modestas. En la catedral y en Santa Maria del Mar, las iglesias más ricas de la ciudad, la diversidad de donativos permite un mayor número de beneficiados, pero también acentúa las diferencias internas. Con estos números, se puede aventurar que estas dos comunidades y las parroquias de Sant Jaume y Sant Cugat eran las vías más propicias para la integración en la estructura eclesiástica urbana de los eclesiásticos de niveles más bajos de renta.

No parece, por el contrario, que fueran también trampolines desde los que acceder a mejores posiciones, aunque hay que recordar que la coyuntura, marcada por el catastrófico asedio de 1697, no es la mejor. Solo en 17 casos (5,3\% del total) de nuestra muestra hay clérigos que han modificado sus condiciones de vida a lo largo del trienio, recogidos en las columnas "evolucionan" y "constituyen/pierden casa" (Tablas 3 y 4). Como norma general, pues, podemos hablar de una gran estabilidad en la situación de los clérigos.

La mayor movilidad se da, precisamente, en Santa Maria del Mar, con 10 casos. Si aceptamos, lo que no está explicitado en ningún sitio, que la primera indicación en el memorial de Taverner corresponde a la situación de 1695 y la segunda a la de 1698, tenemos que 4 beneficiados no tenían casa y han logrado constituirla, 4 que la tenían la han perdido y 2 beneficiados han disminuido en un miembro su familia durante el trienio. Por referirnos a las comunidades ahora citadas, nadie en Sant Jaume o Sant Cugat altera su situación y, de los 63 colegiales de Sant Sever, solo Agustí Ramoneda, pensionado en 1695, tiene casa con dos familiares en 1698.

Además, un canónigo de Santa Anna pasa de vivir con dos familiares a hacerlo con cinco y a un capellán de la Comtessa que tenía tres familiares en 1695, solo le queda uno en 1698. También en el Pi, Sant Just i les Puel·les sendos beneficiados consiguen constituir una casa. Y en Sant Miquel se da el sorprendente caso del Dr. Miquel Barrera, con tres familiares hasta 1697, cuando pasa a residir con siete.

Nuestros datos deben ser relacionados con la peculiar estructura urbanística de Barcelona, en la que abundan los arrendadores. Recordemos que la expresión "tenir casa parada" no se refiere a la propiedad del piso, sino a la existencia de personas

56 Álvarez Santaló, L.C. y García-Baquero, A.: "Riqueza y pobreza del clero secular en la Sevilla del Antiguo Régimen”, Trocadero, 8-9 (1996-97). 
a cargo o servicio del clérigo que conviven con él. En la Barcelona de 1716, 2.304 familias poseían su vivienda, mientras que 5.438 vivían de alquiler. Las diferencias por profesiones eran grandes: más del $60 \%$ de los apotecarios o doctores en derecho eran propietarios, pero solo el $4^{\prime} 8 \%$ de los jornaleros o el $8,8 \%$ de los pescadores ${ }^{57}$. En ese sentido, y aun sin poder saber cuál es la presencia de inquilinos en nuestro grupo de los clérigos con familia, la mera existencia en 1698 de 144 eclesiásticos $(44,8 \%$ del total; ver Tabla 4) que viven pensionados es ya todo un indicio de que no todos gozaban de las comodidades que usualmente se atribuyen a su estamento. La alta demanda y la exigüidad del territorio hacen que el alquiler de los pisos sea alto en Barcelona. Con todo, peor parece la situación en la cosmopolita Sevilla, donde solo el $20 \%$ de una muestra de eclesiásticos del siglo XVIII posee una casa ${ }^{58}$.

De las 5.000 casas barcelonesas en 1716, 64' $8 \%$ son estrechas, de una sola crujía, con entre una y tres habitaciones al lado de una escalera interior, y deben crecer en altura para absorber los aumentos de población (51'9\% de las casas disponen de planta baja y dos pisos). A falta de la confrontación con fuentes notariales, cabe suponer que gran parte del clero secular que tiene uno o dos familiares a su cargo o vive en casa de otras personas debía residir en estos edificios. El tercio restante son fincas más anchas, muchas articuladas alrededor de un patio central. Las más grandes eran unas 340 casas (6' $8 \%$ ) que tenían entre 8 y 10 habitaciones en el primer piso y alojaban a las personalidades más influyentes de la ciudad, con mucho personal de servicio, y a los artesanos más importantes, con su cohorte de aprendices.

Situación diferente era la de los párrocos, que podían vivir en la rectoria, junto con otros clérigos. En la parroquia del Pi, por ejemplo, los tres vicarios compartían ese derecho, lo que, por cierto, obliga al vicario Miquel Busquets, según el propio Taverner, a "sustentar a su madre en el cuarto de una casa"59. Mejor aún era la posición de los canónigos, que disponían de las distinguidas casas que rodeaban la catedral.

\section{Los clérigos: doctorado y parentesco}

Como se ha dicho, en el memorial presentado al Consejo de Ciento se menciona a 321 eclesiásticos. Según nuestra suma, 148 (46\%) de estos beneficiados son doctores, lo que permite pensar en un clero diocesano bien preparado intelectualmente, aunque entre 1650 y 1723 el seminario conciliar de Barcelona permaneció cerrado. En la Tabla 2 se ve, además, que su número se distribuye de manera bastante uniforme por todas las parroquias, siempre en torno a la mitad de los beneficiados, con alguna excepción, como, contra lo que cabría esperar, la modesta parroquia de Sant Jaume, con el mayor porcentaje de doctores $(70 \%)$.

En las corporaciones no parroquiales, la diferencia es notable. Sant Joan $(40 \%)$ y Santa Anna (35\%) están por debajo de la media, y aún más la capilla de la Comtessa, donde solo un beneficiado ha alcanzado el doctorado. ¿Puede ser que en estas tres últimas comunidades, menos vinculadas al servicio pastoral, la selección de personal -cuyos procedimientos son prácticamente desconocidos- diera menos peso a los estudios?

García Espuche, op. cit. (nota 25), p. 82.

Álvarez-Santaló, L.C. y García-Baquero, A., op. cit. (nota 56), p. 24.

Sobre Busquets, Sacasas, op. cit. (nota 43), p. 113. 
En cambio, es dudoso que el Colegio de Sant Sever, a pesar de sus 39 doctores (un sorprendentemente alto 62\%), pudiera funcionar como un vivero de futuros oficiales o incluso canónigos, para los que un doctorado sería un mérito relevante. Faltan estudios diacrónicos para afirmarlo. Con todo, la presencia de doctores entre los canónigos (39\%) y entre los oficiales del cabildo (muy baja: 16\%) en 1702-04, así como la disparidad de apellidos entre esas categorías no abonan dicha hipótesis.

La alta presencia de doctores en el bajo clero secular barcelonés en torno a 1700 plantea cuestiones que, por ahora, no pueden ser resueltas. En toda Europa se ha sostenido que el doctorado era un título caro, al que solo accedían miembros de familias con recursos que, en el caso de los clérigos, aspiraban a obtener las plazas más importantes de las administraciones real y eclesiástica. Pero esta idea no casa con nuestros 148 doctores que ocupan beneficios relativamente modestos en Barcelona, lo que deberá relacionarse, quizás, con el peso social de los estudios universitarios entre las élites catalanas ${ }^{60}$. Tampoco creo que se pueda pensar en un plan deliberado para mejorar la pastoral, pues, curiosamente, el número de doctores es más bajo entre los encargados de la cura de almas: de los 10 párrocos y vicarios mencionados como tales en el documento, solo 4 son doctores ${ }^{61}$.

Desde este punto de vista, una visión panorámica de los apellidos listados por Taverner no invita, salvo nuevos hallazgos, a una visión oligarquizante de las comunidades de beneficiados barcelonesas. Pocas veces el apellido autoriza, hipotéticamente, a entroncar a un clérigo con alguna de las familias que desplegarán procesos de ascensión social durante la centuria, y, en todo caso, su situación personal hacia 1700 parece modesta: Jaume Gònima, sacerdote en el Pi, que ha residido dos años en una posada, sin casa propia ${ }^{62}$; Jacinto Figaró, colegial de Sant Sever, doctor y sin embargo obligado a ejercer de maestro particular ${ }^{63} ; \ldots$ Son excepción los apellidos catalanes de singular prosapia, como los de Gaspar Desprat y Savassona, de Sant Miquel, en pensión, o de Bernat Bòria i Gualba, en les Puel·les, que vive con un solo familiar ${ }^{64}$. En general, los nombres son bastante comunes y se repiten poco, lo que no permite suponer, a falta de pruebas más claras, un sistema generalizado de transmisión de beneficios eclesiásticos mediante resignaciones entre parientes como se ha visto en otros sitios. Cosa muy distinta son los canónigos de la catedral a inicios del siglo XVIII: aquí sí aparecen miembros de las familias nobles catalanas, como los Josa y Agulló, Dalmases, Copons, Sayol i Quarteroni, Taverner i d'Ardena, etc.

En todas las comunidades de beneficiados hay clérigos que viven en casa de parientes, salvo en el Palau de la Comtessa, lo cual indica que se trata de una situación bastante común. En el Antiguo Régimen, la familia es la célula básica de pertenencia y

60 Molas, P.: op. cit. (nota 48), pp. 23-25. Amelang habla de la "nobleza del saber" y de la "asociación" entre clase alta y educación superior; op. cit. (nota 48), pp. 112 y 127.

${ }^{61}$ La relación de Taverner no siempre distingue a los responsables de la cura de almas con precisión. Sobre los párrocos catalanes del siglo XVIII: Puigvert, J.Ma : Església, territori i sociabilitat (s. XVII-XIX), Vic, Eumo, 2001, pp. 53-110.

62 Quizás el sobrino mencionado en el testamento de 1689 de un antepasado del futuro fabricante de indianas. Imbert, E.: Erasmo de Gónima, 1746-1821, Barcelona, s. ed., 1952, p. 22.

63 Aunque el célebre impresor Figueró tenía diversos parientes sacerdotes, este no parece ser uno; Camprubí, X.: L'impressor Rafael Figueró (1642-1726) i la premsa a la Catalunya del seu temps, Barcelona, Fund. Noguera, 2018, pp. 229-232.

64 Hermano de un ciutadà honrat ennoblecido en 1690; Martí Fraga, E.: La classe dirigent catalana. Els membres de la Conferència dels Très Comuns i del Braç Militar (1697-1714), Barcelona, Fund. Noguera, 2009, p. 403. 
solidaridad. El ingreso en el estamento eclesiástico no aleja al clérigo de ella; al contrario, le puede llevar a ejercer nuevos roles $^{65}$. En particular, el clero puede desempeñar, como ha escrito Isidro Dubert, un "carácter asistencial", "una función social de acogida" de familiares a los que habrá que promocionar o de una madre viuda ${ }^{66}$.

La Tabla 5 muestra que solo dos veces el vicario Taverner escribe que un clérigo vive "ab sos parents", sin más precisiones ${ }^{67}$. De los 72 clérigos considerados aquí, 40 viven con sus dos progenitores o con uno de ellos y 25 con sus hermanos. De estos últimos, 21 viven en casa de su hermano y solo 1 en la de su hermana, pero 3 en la del cuñado. En la sociedad patriarcal de la época, estos pueden ser equiparados a los que viven con su hermana, salvando la posibilidad de que ella hubiera fallecido. Se pueden añadir los casos de Josep Socarrats, de la parroquia del Pi, que vive en casa de "su madre y su hermano", y de Onofre Rivas, de Sant Joan, que vivía "antes" en casa de sus padres y "hoy" en la de su cuñado. El peso del primer grado de consanguinidad es, pues, muy fuerte. Solo en dos ocasiones un clérigo vive en casa de su tío y en una, en casa de un sobrino, lo que marca una clara diferencia con otras áreas ${ }^{68}$.

72 casos sobre $321(22,4 \%)$ son un porcentaje bajo con relación al de otras ciudades. En Cádiz, en 1686, sobre dos centenares de clérigos, 25 viven con sus progenitores (de ellos, 20 con su madre), 62 con colaterales (de los que 59 con sus hermanas), 36 con sobrinos o sobrinas (estas son 29) y 14 con diversos parientes, de los que 13 son mujeres $^{69}$. A falta de otras pruebas, la disparidad de la presencia femenina da a entender que la función de protector de las mujeres desvalidas de la familia era más fuerte en el clero andaluz que en el catalán.

Podemos profundizar más en la situación del bajo clero gracias a una segunda relación del mismo legajo del archivo municipal, sin firma ni fecha, que se envió al conseller Bartomeu Roig. En ella se enumeran por el mismo orden que en la relación de Taverner 141 eclesiásticos que no tienen casa parada ${ }^{70}$. Casi siempre este documento repite idénticamente la misma fórmula del primero, salvo algunas veces en las que el autor corrige el cálculo o advierte situaciones particulares, como la del Dr. Tomás Marsal, beneficiado de Sant Sever que vive en casa de su padre, quien es oficial del cabildo y, por lo tanto, exento, por lo que se debe averiguar si este ya ha comprado las mercancías sin pagar aranceles. El autor alerta de que en Santa Maria del Mar hay tres casos en los que dos clérigos de una misma familia conviven, por lo cual, dice, pagarles por separado sería abonar dos veces los gastos de una misma

65 Irigoyen, A.: “Aproximación historiográfica a las relaciones entre clero y familia en la España moderna”, en Sociedade, Família e Poder na Península Ibérica. Elementos para una História Comparativa, Lisboa, Ed. Colibrí - Universidade de Évora - Universidad de Murcia, 2010, pp. 129-149. Una valoración reciente sobre la historia de la familia en Cataluña: Fargas Peñarrocha, M.: "La familia en la Cataluña del Antiguo Régimen (XVI-XVII), 35 años después”, en Alabrús, R.M ${ }^{\mathrm{a}}$ y otros (eds.): Pasados y Presente. Estudios para el Profesor Ricardo García Cárcel, Bellaterra, Universidad Autónoma de Barcelona, 2020, pp. 57-65.

66 Dubert, I.: Historia de la familia en Galicia durante la época moderna, 1550-1830, La Coruña, Edicios do Castro, 1992, pp. 169 y 174.

67 Ellos, Socarrats y Rivas, mencionados más abajo, son los 4 casos de la columna "Indet/Otros".

68 En Santiago, más del 40\% de los clérigos que viven con parientes lo hacen con sobrinos; Dubert, op. cit. (nota 66), p. 175. En Lucena predominan las hermanas, aunque el número de sobrinas es alto; Gómez Navarro, op. cit. (nota 23), p. 353.

69 Morgado, op. cit. (nota 21), p. 145.

70 AHCB, 16. 1C.XVIII- 4 / 15, s.f. "Nota de aquells preveres que no poden entrar en las taxas majors que se son fetes, sino quean de cobrar segons las taxas inferiors". 
casa. A comunidades distintas pertenecen Francisco Garrigó, beneficiado de Sant Miquel, que vive con su hermano Antoni, capellán de la Comtessa, quien ha afirm do tener tres familiares.

En nuestra opinión, este documento fue redactado con la intención de unificar a la baja las tasas de los clérigos que no tenían casa parada, tanto si actuaban como maestros o vivían pensionados o en casa de sus parientes:

Tanto los que están por maestro como los que pagan la posada o están en casa de parientes, aunque paguen la posada, todos se han de regular por una misma tasa, porque no gastan nada por el alimento, sino por el calzado y en eso son iguales en el trato y así todos los sacerdotes de esta calidad se han de regular por la tasa de los que pagan la posada ${ }^{71}$.

Por eso la mayor inquietud del autor estriba en saber, cuando un eclesiástico vive en casa de un pariente, si es o no el cabeza de familia y, por lo tanto, responsable de los gastos de la casa. A veces el declarante ha dicho, sin faltar a la verdad, que vive con sus parientes, pero resulta que son estos los que le "pagan los gastos" o "li fan la vida". En tal situación, se aduce, el clérigo ni siquiera paga por su alojamiento, por lo que debiera cobrar la "tasa ínfima", la de los maestros.

Hay casos peores, pues el clérigo no ha dicho la verdad. Por ejemplo, Mariano Artigas, colegial de Sant Sever, reclama 16 libras y 10 sueldos porque, sostiene, vive con tres familiares. Sin embargo, Artigas vive en casa de su hermana y de su cuñado, que trabaja como sastre. O Pere Gomar, comensal de Santa Anna que pretende tener dos familiares, cuando en realidad vive con su cuñado y su hermana, quienes corren con todos sus gastos. Los mayores defraudadores, presuntamente, serían los doctores Fontcuberta, beneficiados de Santa Maria del Mar. Como Lluís aduce tener cinco familiares y Miquel declara que vive con su hermano, entre ambos se llevarían 28 libras 10 sueldos. Pero los dos viven en casa de su madre, que es la verdadera cabeza de la familia y quien se sospecha que les mantiene.

En el fondo, lo que revela este documento es que en la categoría de los clérigos que viven en casa de sus parientes coexisten dos situaciones. Por un lado, el eclesiástico de una familia más o menos acomodada, que puede vivir tranquilamente en la morada $-\mathrm{y}$ a costa de-sus padres o hermanos, y, por otro, el cura baluarte de la familia que debe hacerse cargo de parientes en situaciones vulnerables, circunstancia que puede darse igualmente en el caso de los clérigos con casa propia y no aparecerá en la relación. Con los datos de que disponemos, es imposible distinguirlas cuantitativamente.

Y es aún más difícil identificar la diversidad de casos oculta bajo la mención de que un clérigo vive en casa de otra persona. Además, este recibe la misma cantidad que el clero "a dispesa", por lo que cabe suponer que el vicario no sería muy escrupuloso a la hora de diferenciar ambas situaciones. En ese sentido, la presencia de sacerdotes en casa de otras personas sin ningún vínculo familiar era habitual en el Antiguo Régimen. Como en muchas otras ciudades, esto ocurre en el caso de las élites, que protegen y/o emplean clérigos a su servicio. El documento municipal del

\footnotetext{
"Tant los que estan per Mestre com los que pagan la dispesa o estan en casa de parents encara que pagaren la despesa tots se an de regular per una mateixa taxa, perque no gastan cosa per lo victo, sino per lo calçar y en axo son iguals ab lo tractament y aixi tots los sacerdots desta calitat se an de regular a la taxa dels qui pagan la despesa".
} 
que hablamos menciona a Pau Borras, beneficiado de Santa Maria del Mar que vive en casa de Don Josep de Pinós; Josep Bertolí, clérigo de Sant Joan de Jerusalem, que habita en casa del Dr. Miquel Pallarés, y Gaspar Ferrer, beneficiado de Santa Maria del Pi que vive en casa del propio Bartomeu Roig, notario regio, conseller del municipio y destinatario de este mismo texto.

Sabemos que muchas de las mejores y más amplias casas de la ciudad disponían de una capilla. No son solo las mansiones nobles, sino también, por ejemplo, la casa del médico Fermí Poal en 1683 o la del notario Francesc Lentiscla en $1689^{72}$. No sería extraño que las familias con posibles, que intentaban emular a la nobleza para acceder a ella, tuvieran un sacerdote en casa para asegurar un culto doméstico, tanto si disponía también de las rentas de un benefício en la ciudad como si no. Porque la bibliografía nos informa de casos como el del mercader Francesc Jofré, que en 1716 vive de alquiler en una casa de la calle Montcada junto con su esposa, dos hijos, dos criadas, un clérigo y un niño ${ }^{73}$.

Valga el ejemplo del notario Ramon de Vilana Perlas, casado con Eulàlia Camarasa, cuyo hermano sacerdote, Sebastià, cede en 1669 todos sus bienes al cuñado. Ramon, a cambio, acoge en su casa al eclesiástico y asumirá todos sus gastos de alimentación, vestido y atención médica. El Rdo. Camarasa será beneficiado de las parroquias de Vilassar y de Santa Maria del Mar de Barcelona. En 1672, los Vilana Perlas compran una gran casa, con capilla incluida, en la calle Regomir. Sebastià sigue con ellos, convertido en "clérigo de la casa", incluso después de la muerte de Eulàlia en 1676. A principios de esa década viven en la mansión 15 personas: los dos cónyuges, sus cuatro hijos, los tres escribientes de la notaría, un familiar, cuatro personas de servicio y el presbítero.

A su vez, Ramon tiene un hermano sacerdote, Tomàs, párroco de un pequeño pueblo de la diócesis de Urgell, de donde provenía la familia, pero que también se ha mudado a Barcelona. Tomàs reside en una casa propiedad del yerno de Vilana Perlas al lado de la iglesia de Sant Miquel, a cuya comunidad de beneficiados pertenece hasta su deceso en 1688. Los Vilana Perlas serán pronto "ciudadanos honrados" y el hijo del notario, Ramon de Vilana Perlas i Camarasa (1663-1741) alcanzará en 1710 el título de marqués de Rialp ${ }^{74}$. Sin embargo, Sebastià Camarasa, que murió en 1702, no está en la lista de los sacerdotes que cobran el indiviso entre 1695 y 1698. ¿Es que quizás no residía en Barcelona en aquel momento?

Aun así, el vacío más llamativo en nuestro documento es el del más célebre beneficiado barcelonés de la historia, el Dr. en Teología Josep Oriol i Bogunyà (16501702), canonizado en 1909 por su abnegada dedicación a los pobres. Este hijo de un terciopelero barcelonés, huérfano de padre al poco de nacer, se ordenó sacerdote en 1676 y fue luego preceptor de dos niños, por lo que no se sabe si continuó viviendo con su madre en la calle Xuclà o pasó a la residencia de aquellos, en la actual Plaza Real. Oriol tomó posesión de un beneficio en Santa Maria del Pi en 1687. Por entonces, ya fallecida su madre, vivía como realquilado en casa de una señora, en la calle de la Flor. En 1698 realizó una peregrinación a Roma que no llegó a completar, $\mathrm{y}$, aunque en mayo ya estaba de vuelta a Barcelona, quizás ese es el motivo de su ausencia en la relación de Taverner, pero después sí aparece entre los receptores del

García Espuche, op. cit. (nota 34), v. 1, p. 168.

Ibidem, v. 2, p. 73.

García Espuche, op. cit. (nota 22), pp. 205-215. 
indiviso desde 1698 a 1701 como "estant en casa de altre", tal vez la casa de la calle Daguería en la que murión ${ }^{75}$.

Los hagiógrafos subrayan los vínculos de Josep Oriol con la rica familia Milans, de Canet de Mar. Marc Antoni Milans confió la educación de varios de sus hijos a Oriol, quien a menudo los alojaba en su casa de Barcelona. La amistad del santo con el organista del Palau de la Comtessa, Jeroni Oller, oriundo también de Canet, le permitió introducir a dos de ellos, Tomàs y Carles, en la escolanía de esta institución y descubrir así las excelentes dotes musicales del primero, quien fue desarrollando en paralelo sus carreras artística y clerical. Cuando en 1699 se jubiló el maestro de la capilla, Felip Olivelles, fue sustituido por Gabriel Aragany y este, a su vez, en 1701, por el propio Tomàs Milans, por entonces subdiácono, quien ejerció hasta $1714^{76}$.

En la relación del indiviso del trienio 1695-98, Felip Olivelles recibe 24 libras por los diez miembros de su familia, ya que, como hemos dicho, los niños de la escolanía debían vivir con el maestro. Por entonces, Tomàs Milans vive en pensión y debió recibir con alivio las 7 libras 10 sueldos que le correspondían por el indiviso durante los tres años anteriores, a la espera de los tiempos de gloria musical y crematística que le llegarían con el siglo XVIII.

He aquí, pues, como botón de muestra, a algunos de nuestros beneficiados sin casa propia: el hermano y el cuñado de un notario venido del Urgell, que se codean con la alta sociedad local; el modesto huérfano de un artesano barcelonés, realquilado y cambiando de piso toda su vida; un músico llegado del Maresme que con el tiempo alcanzará la fama... El consumo personal y la contribución a los gastos de sus casas comprando productos al por menor, que es lo que justifica la devolución del indiviso, forzosamente tenían que ser distintos en estos casos.

\section{Conclusión}

La relación del vicario Taverner trasluce, en primer lugar, una gran estabilidad. Son muy pocos los clérigos que cambian de situación entre 1695 y 1698, y no siempre a mejor, aunque es cierto que el número de beneficiados presentes en la lista es más bajo del que debería ser. En segundo lugar, indica las grandes diferencias dentro del estamento. Personalidades ricas e influyentes, como Tolleuda, coexisten con clérigos de rentas parvas forzados a trabajar como preceptores, vivir a pensión en habitaciones alquiladas o mantener a algunos de sus parientes con su beneficio

En relación con las fuentes usadas en otros lugares, como el Catastro de Ensenada $^{77}$, la ventaja de la documentación barcelonesa de 1698 es que revela el peso de este sector inferior del bajo clero que no actúa como cabeza de familia, que supone casi la mitad de la muestra (44’8\%). Además, nos permite distinguir entre el clero adscrito al culto parroquial y el de otras corporaciones. A diferencia del catastro, en cambio, no nos autoriza a decir cuáles de estos eclesiásticos eran cabezas de su hogar, lo que, como hemos visto, preocupaba a las autoridades municipales.

\footnotetext{
APSMP - B 393.

76 Gregori, J.M.: "Tomàs Milans i Godayol, escolà i mestre de capella del Palau de la Comtessa (c. 1680-1714) i la seva relació amb Sant Josep Oriol", Revista Catalana de Musicologia, 7 (2014), pp. 39-90.

77 Sobre su potencialidad, Gómez Navarro, op. cit. (nota 23), pp. 343-369.
} 
Taverner muestra la diferencia de efectivos y de nivel de riqueza entre las siete parroquias de la ciudad, cosa ya más o menos sabida. Destacan la iglesia de Santa Maria del Mar, con 105 beneficiados, y la de Santa Maria del Pi, con 28, por su nivel de renta. Son las dos primeras en el protocolo de la ciudad y sirven a los dos "centros" urbanos definidos por García Espuche, el comercial y el político. En el otro extremo del arco, las parroquias de Sant Cugat y de Sant Jaume se revelan de una gran humildad, casi impropia de la ciudad rica y populosa en la que están situadas.

La relación nos muestra también la importancia de cuatro corporaciones que, hasta ahora, apenas han merecido la atención de los historiadores. En la colegiata de Santa Anna, el priorato de Sant Joan de Jerusalem, la capilla del Palau de la Comtessa y el colegio de Sant Sever sirven 106 beneficiados, el 33\% del bajo clero secular de Barcelona. Especialmente llamativa es la dimensión de esta última institución, que agrupaba a 63 eclesiásticos del bajo clero de la catedral. Las diferencias de rentas con los canónigos del cabildo son, como era de esperar, notables.

Sorprende también el alto número de doctores universitarios $(46 \%)$ y el bajo número, en comparación con otras ciudades, de eclesiásticos que viven con sus parientes (22'4\%). Entre estos, casi todos residen con sus progenitores o sus hermanos y hermanas. Estos rasgos quizás se pueden atribuir a las particularidades de la sociedad catalana moderna: la importancia del saber universitario para la promoción social, por un lado, y el alto precio de los alquileres (iya entonces!), por otro.

A título comparativo, los estudios de Isidro Dubert sobre los hogares del clero en Santiago de Compostela a partir de la documentación notarial y del Catastro de Ensenada presentan un clero bajo y medio que convive con entre 1 y 3 criados. La media es de 2,3 individuos por hogar de eclesiástico, próxima a la de los sectores urbanos gallegos más empobrecidos. La mayoría de este clero vive de alquiler en residencias modestas, normalmente con tres habitaciones (salón, cocina y el cuarto de la criada). Dubert subraya que el $53 \%$ del bajo clero convive con parientes, aunque no podemos asimilar directamente esa categoría a los 72 clérigos que viven con sus parientes en Barcelona (22\%), puesto que esta última cifra engloba solo a aquellos que no tienen casa propia ${ }^{78}$.

En Murcia, Antonio Irigoyen, tomando también las respuestas al Catastro, establece que, sobre 300 clérigos estudiados, 90 viven con un solo familiar, 66 con dos o tres, 50 con cuatro y 56 con cinco o seis personas ${ }^{79}$. Su investigación pone de relieve que las familias de estos eclesiásticos son mucho más numerosas que las del clero barcelonés, pero habría que ver si ello se debe a la evolución alcista del XVIII, puesto que medio siglo separa sus datos de los nuestros, o a diferencias de contexto que siempre deben ser tenidas en cuenta. Por ejemplo, en Cádiz, en 1694, cuando ya se augura el gran siglo de esplendor mercantil de la ciudad, según Arturo Morgado la familia media de los prebendados de la catedral es de 10 personas. Por la misma época, en Galicia, es de 5,7 individuos en el alto clero ${ }^{80}$.

78 Dubert, I.: "Los comportamientos del clero urbano en Galicia: el ejemplo de Santiago de Compostela en el siglo XVIII”, Compostellanum, 1986 (31), pp. 443-455. Op. cit. (nota 66), p. 175.

79 Irigoyen, A.: "Aproximación al estudio del servicio doméstico del alto clero de Murcia durante el siglo XVIII", Obradoiro de Historia Moderna, 19 (2010), pp. 307-327.

80 Morgado García, A.: "Vida de canónigo. Percepción, origen y status de vida del alto clero durante el Antiguo Régimen”, en Aranda Pérez, F.J.: Sociedades y élites eclesiásticas en la España moderna, Cuenca, Universidad de Castilla-La Mancha, 2000, p. 94. En 1686, la media de la familia clerical gaditana era de 4,7 personas en general y de 9,7 en el cabildo; Morgado, op. cit. (nota 21), p. 143. 
La documentación estudiada nos ofrece una fotografía de la población eclesiástica secular en Barcelona en el tránsito hacia el siglo XVIII. Queda por estudiar su evolución, tanto en términos cuantitativos como cualitativos. En el estado actual de nuestros conocimientos, no podemos establecer si los beneficiados y capellanes de rango más bajo conseguían regularmente ascender a posiciones mejores o si los grupos que hemos visto forman compartimentos poco permeables, en los que el origen social y familiar de cada clérigo condiciona el nivel de renta y el tipo de vida a los que puede aspirar. La poca repetición de los apellidos en la lista del vicario Taverner, a diferencia de lo que suele ocurrir en las nóminas de los cabildos catedralicios, y el hecho de que solo 10 de los 321 clérigos censados consigan entre 1695 y 1698 cambiar su situación constituyendo una familia propia o acrecentándola invitan a pensar que la segunda posibilidad es la más probable.

En 1700, la Confraternidad de Sant Sever y el Consejo de Ciento negociaron las nuevas tasas anuales que se pagarían a partir de entonces por el indiviso clerical, que resultaron ligeramente inferiores a las fijadas un año antes. Pero la supresión del Consejo de Ciento por Felipe V en 1714 acaba abruptamente con las series archivísticas en las que hemos hallado estos documentos. Sin embargo, no se modificó el sistema, sino solo el cálculo: en 1715 se negociaron nuevas condiciones ${ }^{81}$. Hasta bien avanzado el siglo XIX, los beneficiados barceloneses fueron recibiendo cada año su cuota. Por eso, es de esperar que nuevos hallazgos documentales permitan reconstruir la historia de esta singular tasa y, con ella, conocer la evolución del bajo clero secular en Barcelona.

\section{Bibliografía}

Álvarez-Santaló, L.C., García-Baquero, A.: "Riqueza y pobreza del clero secular en la Sevilla del Antiguo Régimen", Trocadero, 8-9 (1996-97), pp. 11-46.

Amelang, J.: La formación de una clase dirigente. Barcelona, 1490-1714, Barcelona, Ariel, 1986.

Bada Elías, J.: "L'origen del clergues barcelonins en el segle XVII (1635-1717). Aproximació estadística", en Homenatge al Doctor Sebastià García Martínez, Valencia, Generalitat Valenciana, 1988, vol II, pp. 201-213.

Bada Elías, J.: "Iglesia y sociedad en el Antiguo Régimen: el clero secular", en Martínez Ruiz, E. y Suárez Grimón, V. (eds.): Iglesia y sociedad en el Antiguo Régimen, Las Palmas, AEHM - Universidad de Las Palmas de Gran Canaria, Las Palmas de Gran Canaria, 1994, pp. 81-91.

Barrio Gozalo, M.: El clero en la España moderna, Córdoba, Cajasur, 2010.

Callado Estela, E. (ed.): Gloria, alabanza y poder. Cabildos catedrales hispánicos en la Época Moderna, Madrid, Sílex, 2021.

Camprubí, X.: L’impressor Rafael Figueró (1642-1726) i la premsa a la Catalunya del seu temps, Barcelona, Fund. Noguera, 2018.

Camprubí, X.: Els mestres de minyons i l'ensenyament públic a la Barcelona moderna (segles XVI-XVIII), en prensa.

Candau Chacón, M. ${ }^{a}$ L.: Los delitos y la penas en el mundo eclesiástico sevillano, Sevilla, Diputación Provincial, 1993.

$81 \quad$ APSMP, C-746, no 4 . 
Candau Chacón, $\mathrm{M}^{\mathrm{a}} \mathrm{L} .:$ La carrera eclesiástica en el siglo XVIII. Modelos, cauces y formas de promoción en la Sevilla rural, Sevilla, Universidad de Sevilla, 1993.

Dantí, J.: "La hacienda municipal y las exenciones fiscales en Catalunya. El conflicto entre el Consejo de Ciento y los eclesiásticos en Barcelona en los siglos XVI y XVII”, en Bernardo Ares, J. M. y González Beltrán, J. M. (eds.): La Administración Municipal en la Edad Moderna, Cádiz, FEHM- Universidad de Cádiz, 1999, pp. 219-228.

Diccionario de la Lengua Castellana... Tomo Tercero, Madrid, Real Academia Española, 1723.

Dubert, I.: Historia de la familia en Galicia durante la época moderna, 1550-1830, La Coruña, Ed. do Castro, 1992.

Dubert, I.: "Los comportamientos del clero urbano en Galicia: el ejemplo de Santiago de Compostela en el siglo XVIII", Compostellanum, 31 (1986), pp. 443-455.

Espino López, A.: Catalunya durante el reinado de Carlos II, Bellaterra, Universitat Autònoma de Barcelona, 1999.

Fargas Peñarrocha, M.: "La familia en la Cataluña del Antiguo Régimen (XVI-XVII), 35 años después”, en Alabrús, R.M ${ }^{\mathrm{a}}$ y otros (eds.): Pasados y Presente. Estudios para el Profesor Ricardo García Cárcel, Universitat Autònoma de Barcelona, Bellaterra, 2020, pp. 57-65.

Fatjó Gómez, P.: "Las haciendas eclesiásticas en la Catalunya del XVIII", en Església i societat a la Catalunya del segle XVIII, Cervera, UNED, 1990, pp. 119-145.

Fatjó Gómez, P.: La catedral de Barcelona en el siglo XVII: las estructuras y los hombres, tesis doctoral, Universidad de Barcelona, 2000.

Feliu, G.: Precios y salarios en la Cataluña Moderna, Madrid, Banco de España, 1991.

Fernández Díaz, R.: "La clerecía catalana en el Setecientos", en Església i societat a la Catalunya del segle XVIII, Cervera, UNED, 1990, pp. 23-118.

Fernández Terricabras, I.: "No King for a Palace. Royal Palaces in Barcelona in the Seventeenth Century", en Hortal Muñoz, J.E.: Politics and Piety at the Royal Sites of the Spanish Monarchy in the Seventeenth Century, Turnhout, Brepols, 2021, pp. 99-115.

Fortea, J.I. y Gelabert, J.E.: "Fraude y fisco a comienzos de los tiempos modernos, una historia interminable", en Fortea, J.I., Galán, A. y Gelabert, J.E. (eds.): Siete siglos de fraude fiscal en Europa, Universidad de Cantabria, Santander, 2020, pp. 49-80.

García Espuche, A.: Barcelona entre dues guerres. Economia i vida quotidiana (1652-1714), Vic, Eumo, 2004.

García Espuche, A.: La ciutat del Born. Economia $i$ vida quotidiana a Barcelona (segles XIV a XVIII), Barcelona, Ajuntament, 2009.

García Espuche, A.: La gent del carrer Montcada. Una història de Barcelona (segles XIII a XVIII), Barcelona, Ajuntament, 2020.

García González, F. (ed.): Vivir en soledad: viudedad, abandono y soltería en el mundo rural (España y América Latina, siglos XVI-XXI), Madrid, Iberoamericana, 2020.

Gómez Navarro, S.: "Familia, estamento e institución: el clero secular en el Reino de Córdoba a mediados del siglo XVIII. El caso de Lucena", Studia Histórica. Historia Moderna, 35 (2013), pp. 343-369.

Gómez Navarro, S.: "La familia religiosa en la España Moderna. Balance y propuesta analítica”, Historia Social, 92 (2018), pp. 119-138.

Gómez Navarro, S.: "La institución parroquial católica en el Antiguo Régimen. Propuesta de análisis y estado de la cuestión”, Vínculos de Historia, 9 (2020), pp. 246-271.

Gregori i Cifré, J.M": "Tomàs Milans i Godayol, escolà i mestre de capella del Palau de la Comtessa (c. 1680-1714) i la seva relació amb Sant Josep Oriol”, Revista Catalana de Musicologia, 7 (2014), pp. 39-90. 
Guàrdia Bassols, M. y García Espuche, A.: "Estructura urbana", en Sobrequés, J. (dir.): Història de Barcelona, vol. 4, Barcelona, Ajuntament, 1992, pp. 43-101.

Imbert, E.: Erasmo de Gónima, 1746-1821, Barcelona, s. ed., 1952.

Irigoyen López, A.: "Las aportaciones de la historia de la familia a la renovación de la Historia política y a la Historia de la Iglesia", en Poblaciones históricas. Fuentes, métodos y líneas de investigación, Río de Janeiro, Asociación Latinoamericana de Población, 2009, pp. 345-362.

Irigoyen López, A.: “Aproximación historiográfica a las relaciones entre clero y familia en la España moderna”, en Sociedade, Família e Poder na Península Ibérica. Elementos para una História Comparativa, Ed. Colibrí, Universidades de Évora y de Murcia, Lisboa, 2010, pp. 129-149.

Irigoyen López, A.: “Aproximación al estudio del servicio doméstico del alto clero de Murcia durante el siglo XVIII”, Obradoiro de Historia Moderna, 19 (2010), pp. 307-327.

Jiménez Sureda, M.: L'Església catalana sota la Monarquia dels Borbons. La catedral de Girona en el segle XVIII, Publicacions de l'Abadia de Montserrat, Barcelona, 1999.

Lavenia, V.: "La Teología y la evasión fiscal (siglos XVI-XVII)", Fortea, J.I., Galán, Á. y Gelabert, J.E. (eds.): Siete siglos de fraude fiscal en Europa, Santander, Universidad de Cantabria, 2020, pp. 81-116.

Martí Fraga, E.: La classe dirigent catalana. Els membres de la Conferència dels Très Comuns i del Braç Militar (1697-1714), Barcelona, Fund. Noguera, 2009.

Molas Ribalta, P.: La burguesía mercantil en la España del Antiguo Régimen, Madrid, Cátedra, 1985.

Morgado García, A.: El estamento eclesiástico y la vida espiritual en la diócesis de Cádiz en el siglo XVII, Cádiz, Universidad de Cádiz, 1996.

Morgado García, A.: "Vida de canónigo. Percepción, origen y status de vida del alto clero durante el Antiguo Régimen", en Aranda Pérez, F.J.: Sociedad y élites eclesiásticas en la España moderna, Cuenca, Universidad de Castilla-La Mancha, 2000, pp. 77-101.

Morgado García, A.: "El clero en la España de los siglos XVI y XVII. Estado de la cuestión y últimas tendencias”, Manuscrits. Revista d'Història Moderna, 25 (2007), pp. 75-100.

Puigvert, J. Mª : Església, territori i sociabilitat (s. XVII-XIX), Vic, Eumo, 2001.

Puigvert, J. Ma: "Los párrocos y las redes de sociabilidad parroquial en el mundo rural de la Cataluña Moderna: historiografía e historia”, Obradoiro de Historia Moderna, 22 (2013), pp. 167-206.

Rifé i Santaló, J.: "La música al Palau de la Comtessa de Barcelona durant el govern de l'Arxiduc Carles d'Àustria a Catalunya (1705-1714)", Revista Catalana de Musicologia, 2 (2004), pp. 131-143.

Sacasas i Segura, J.: "La funció de la parròquia com a centre i nexe social a la ciutat assetjada. L'exemple de Santa Maria del Pi (1705-1730)", en Boada, C. y Brugués, I. (eds.): L'Església a Catalunya durant la Guerra de Successió, Publicacions de l'Abadia de Montserrat, Barcelona, 2015, pp. 99-125.

Sacasas i Segura, J.: "Origen i consolidació de la comunitat parroquial de Santa Maria del Pi i el seu arxiu”, en Splendor Pinensis. Santa Maria del Pi al segle XV, Barcelona, Ateneu Universitari Sant Pacià, 2019, pp. 59-98.

Sacasas i Segura, J.: "La Venerable Confraternitat de Sant Sever de Barcelona, un "sindicat" del segle XVI”, Basílica de Santa Maria del Pi. Ahir, avui, demà, 804 (20/10/2020), https://basilicadelpi.cat/wp-content/uploads/2020/10/804.pdf

Simon i Tarrés, A.: Del 1640 al 1705. L'autogovern de Catalunya i la classe dirigent catalana en el joc de la política internacional europea, Valencia, Publicacions de la Universitat, 2011. 
Simon i Tarrés, A.: Els orígens del miracle econòmic català, Barcelona, Rafael Dalmau, 2021.

Vilamala Salvans, J.: Una Seu, dos col-legis: la comunitat de beneficiats de l'església de la Pietat de Vic (1613-1664), tesis doctoral, Universidad de Barcelona, 2019.

Zamora Bretones, Montserrat: La ciudad y el templo: religión cívica en la Barcelona moderna (XVI-XVIII), tesis doctoral, Universitat de Girona, 2020.

\section{Tabla 1}

Cantidad cobrada por el indiviso en cada corporación de Barcelona y número de clérigos en ellas (1695-98), complementada con los datos del indiviso del cabildo catedral en 1702-1704.

\section{CLÉRIGOS LIBRAS SUELDOS}

LIBRAS/

\section{CLERO NO PARROQUIAL:}

ST. SEVER

STA. ANNA

JERUSALEM

COMTESSA

Subtotal

PARROQUIAS:

STA. Ma MAR

PI

STS. JUST I PASTOR

ST. MIQUEL

ST. PERE

ST. JAUME

ST. CUGAT

Subtotal

TOTAL

CATEDRAL (1702-1704)

Dignidades, canónigos

1112

362

201

239

253

93

52

2315

3448

$\mathrm{y}$ beneficiado

Subtotal
PERS

$\begin{array}{rrr}611 & 9 & 9,69 \\ 209 & 6 & 12,29 \\ 110 & 6 & 11 \\ 202 & 8 & 12,62 \\ \mathbf{1 1 3 3} & 9 & \mathbf{1 0 , 6 8}\end{array}$

10,59

12,92

10,05

10

10,74

11,38

10,12

9,3

8,66

10,76

1
831

25,18

667

3

13,89

3

18,49

Fuente: AHCB, 16.1C.XVIII- 4 / 15 y 16.1B.XII-35, f. 323-502. 


\section{Tabla 2}

Presencia de doctores en el clero secular de Barcelona (1695-1698) complementada con los datos del cabildo catedral en 1702-1704.

TOTAL Doctores \%

\section{CLERO NO PARROQUIAL:}

ST. SEVER

STA. ANNA

JERUSALEM

COMTESSA

Subtotal

PARROQUIAS:

STA. Ma DEL MAR

PI

ST. JUST I PASTOR

ST. MIQUEL

ST. PERE

ST. JAUME

ST. CUGAT

Subtotal

TOTAL

CATEDRAL (1702-1704)

Dignidades y canónigos

Beneficiado

Subtotal

$\begin{array}{lll}63 & 39 & 61,9\end{array}$

17

10

16

106

105

50

47,6

28

12

42,8

20

11

55

215

321
33

21

25

10

6

148

46,1

23,8

40

70

50

45,5

$98 \quad 45,5$

48

13

39,3

8

16,6

81
21

25,9

Fuente: AHCB, 16.1C.XVIII- 4 / 15 y 16.1B.XII-35, f. 323-502. 


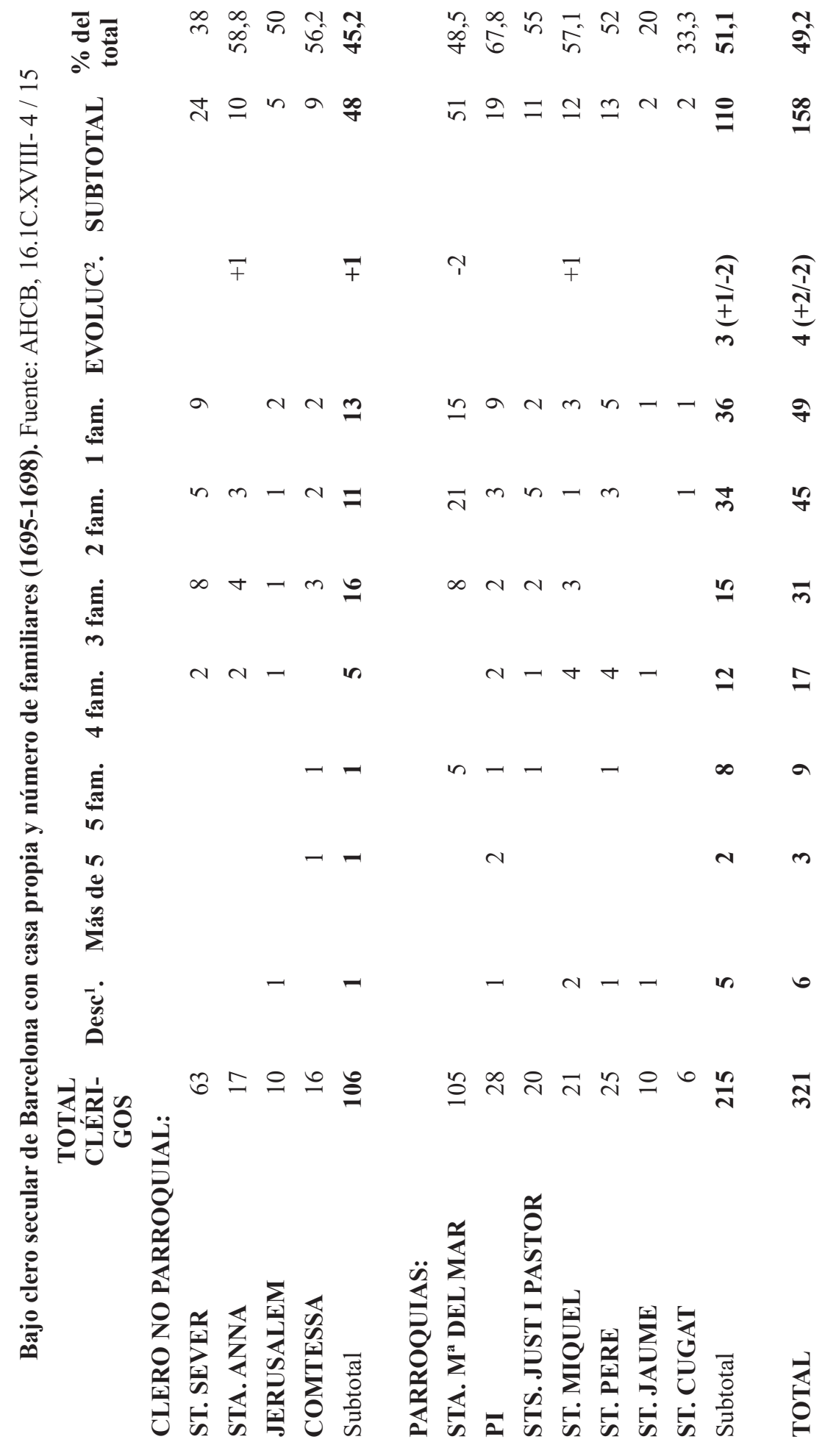

Desconocidos: Estos clérigos, cuya situación familiar no está indicada en la relación del vicario Taverner, no están sumados en la columna "subtotal" de esta tabla.

2 Evolucionan: beneficiados que entre 1695 y 1698 aumentan el número de familiares que viven con ellos (signo positivo) o lo disminuyen (signo negativo). 


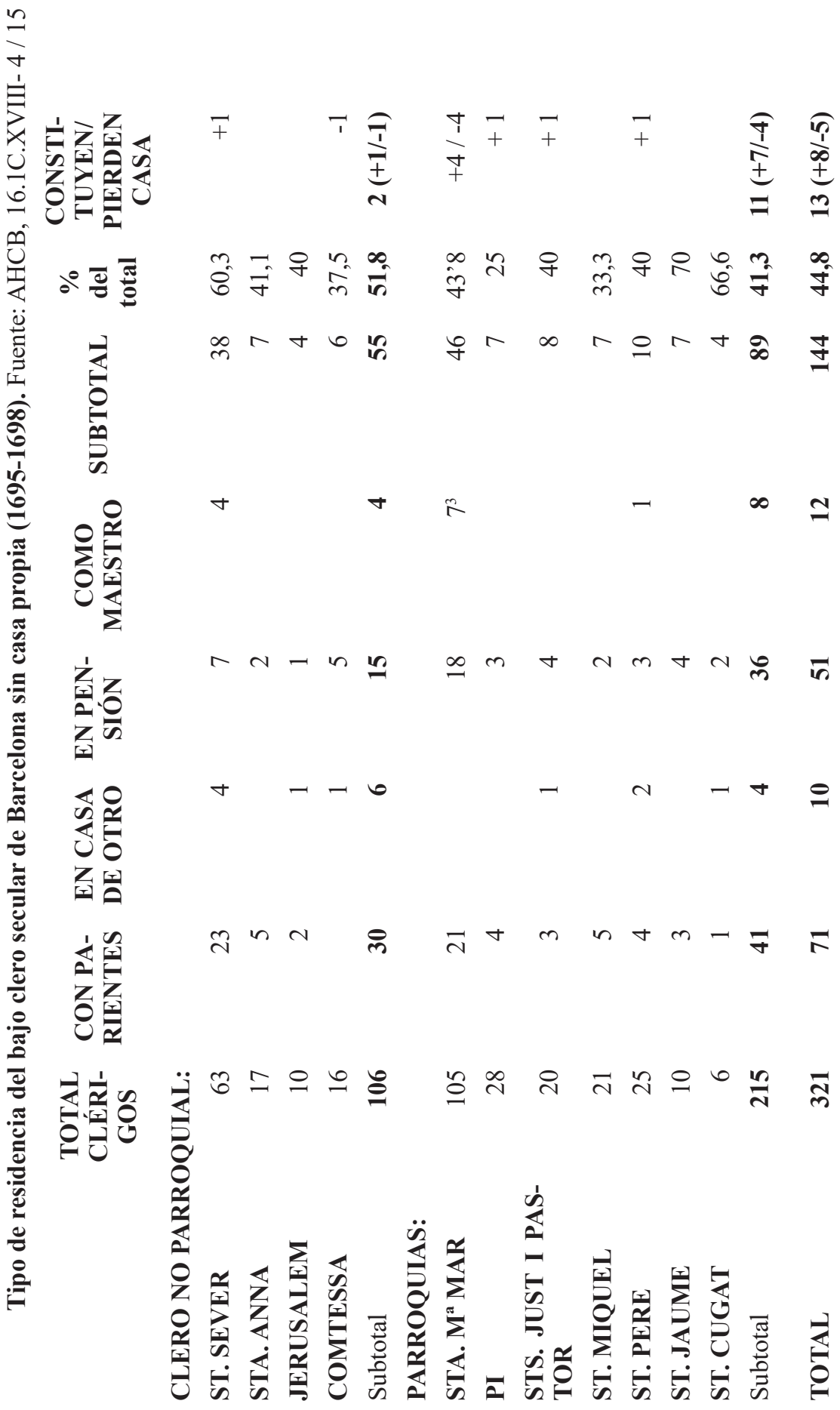




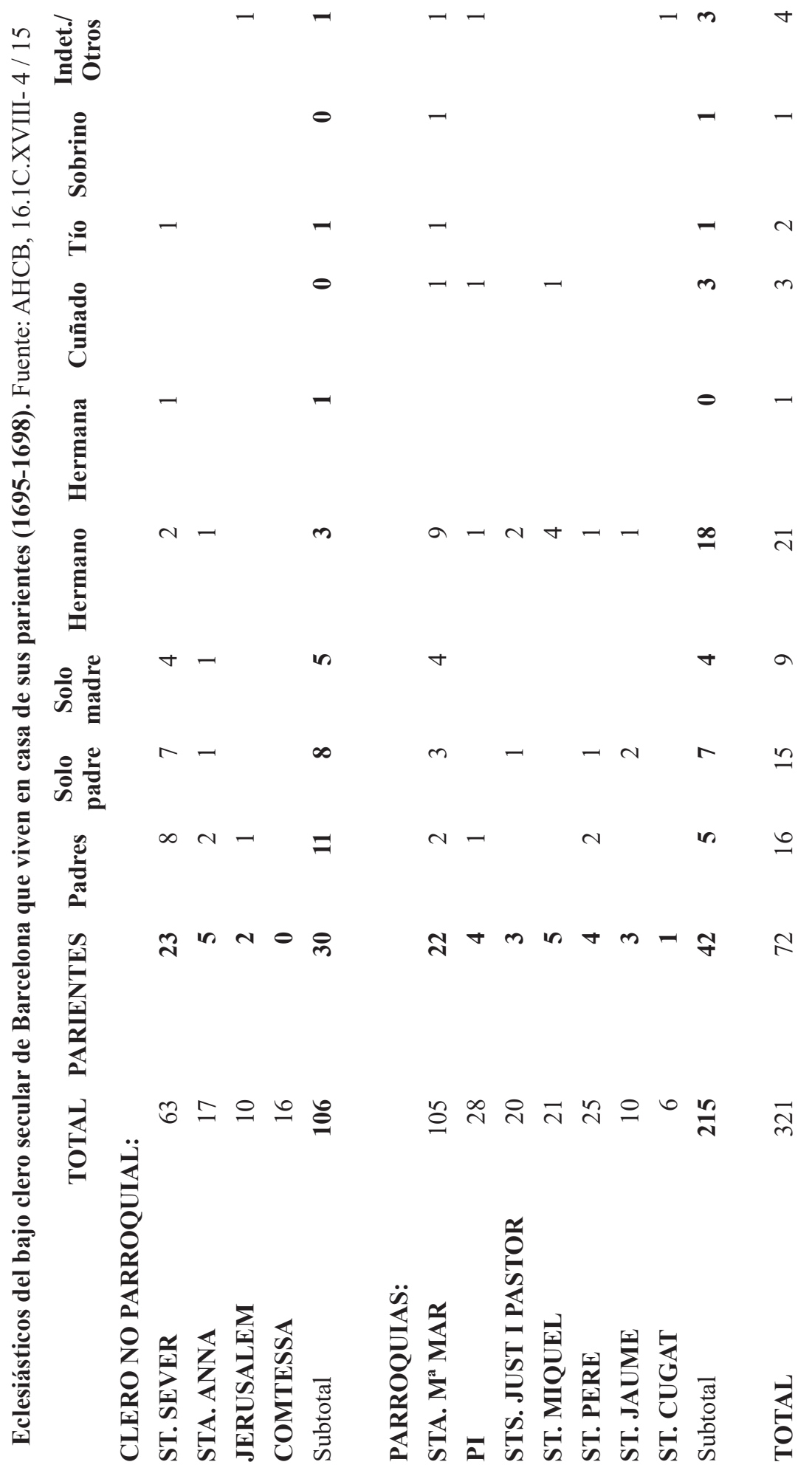

